\title{
LA VULNERABILIDAD EN LAS ESTRUCTURAS Y PROCESOS DEMOGRÁFICOS DEL CHACO
}

\author{
DRA. ANA MARIA FOSCHIATTI (1) \\ Departamento de Geografía \\ Facultad de Humanidades \\ Universidad Nacional del Nordeste (Ar- \\ gentina) \\ Avenida Las Heras $N^{\circ} 727$ - \\ 3500 - Resistencia - Chaco - Argentina \\ Teléfono/FAX: $0054-3722-446958$
}

RESUMEN

Este trabajo incluye el tratamiento de los cambios y tendencias de las variables demográficas y su relación con la vulnerabilidad social de la provincia del Chaco. La peculiar dinámica demográfica de los más vulnerables que se caracteriza por patrones de mortalidad, fecundidad y de otros rasgos demográficos distintivos, con índices de dependencia muy altos, merece ser tenida en cuenta a la hora de esbozar intervenciones preventivas de las áreas estudiadas. Esto reviste particular importancia por cuanto en los últimos tiempos el país y la región han experimentado cambios profundos de su comportamiento demográfico. Son variadas y amplias las dimensiones de esos cambios: la esperanza de vida ha aumentado considerablemente, el promedio de hijos por mujer disminuyó y la proporción de niños y ancianos han registrado diferencias. Asimismo la población que reside en áreas urbanas, la participación laboral femenina, la migración interna, entre otros indicadores también demostraron cambios cuantitativos y cualitativos. Estas modificaciones se traducen en un panorama muy heterogéneo de la dinámica demográfica donde los grupos vulnerables presentan un singular comportamiento de sus estructuras sociales y un fuerte impacto en la sociedad.

\section{PALABRAS CLAVES}

$<$ Vulnerabilidad $><$ Estructuras demográficas $><$ Procesos demográficos $><$ Chaco $>$

\section{SUMMARY}

This work includes the treatment of changes and tendencies of demographic variables and their relation with social vulnerability in the province of Chaco.

The unique demographic dynamics of the most vulnerable people, which is characterized by mortality patterns, fertility and other distinguishing demographic features, with very high indices of dependency, has to be taken into account when outlining preventive interventions of the areas under studies.

This has greater importance inasmuch as lately the country and the region have experienced deep changes in their demographic behaviour.

The dimensions of those changes are varied and ample: life expectancy has increased considerably, the average number of children per woman has diminished and the proportion of old people and children has scored differences.

Besides, the urban population, the women participation in the labour market and the internal migration among other indicators, have shown quantitative and qualitative changes.

These changes are reflected in a very heterogenous scenery of demographic dynamics where the vulnerable groups display a singular behaviour of their social structures and a strong impact in society.

\footnotetext{
KEY WORDS

$<$ Vulnerability $><$ Demographic structures $><$ Demographic processes $><$ Chaco $>$
} 


\section{PRESENTACION}

Este trabajo tiene la intención de brindar un marco conceptual y metodológico para el tratamiento de los problemas de la vulnerabilidad en las estructuras y procesos demográficos en la provincia del Chaco, a partir de indicadores seleccionados. Se pretende mostrar el comportamiento de las variables, con el objeto de que a partir de su conocimiento se tomen decisiones tendientes a mejorar las condiciones de vida de la población.

Los estudios de vulnerabilidad se distinguen por su capacidad de anticipar acontecimientos demográficos, aún los que implican riesgos sociodemográficos. Esto ocurre particularmente porque los procesos de cambio demográfico operan en períodos de tiempo relativamente extensos y tienen la peculiaridad de iniciarse en algunos espacios geográficos y expandirse luego a otros. Los cuatro procesos que se vinculan con la vulnerabilidad sociodemográfica estructuran las condiciones demográficas presentes y futuras. Elos son: la transición demográfica, la transición urbana y de la movilidad, la segunda transición demográfica y la transición epidemiológica.

En este caso el análisis y la evaluación de su vulnerabilidad en la provincia del Chaco permite detectar áreas susceptibles, diagnosticar la calidad de vida de la población, comparar el estado del equipamiento de los servicios, analizar factores socioculturales que influyen en las vulnerabilidades regionales. De allí la importancia de su estudio conceptual, metodológico y empírico para comprender la percepción de la población acerca de sus riesgos, analizar pautas de comportamiento, evaluar actitudes y prácticas y formular recomendaciones para implementar políticas públicas al respecto. 


\section{Lavulnerabilidad en lasetructurasy procesos demogóficos dd Chaco}

\section{INDICE}

La vulnerabilidad en las estructuras y procesos demográficos del Chaco

Página

Presentación 1

1. La vulnerabilidad asociada a las variables demográficas 5

2. La vulnerabilidad asociada a los procesos demográficos 9

2.a. La transición demográfica 9

2.b. La transición urbana y de la movilidad 12

2.c. La segunda transición demográfica 18

2.d. La transición epidemiológica 22

3. La vulnerabilidad asociada a la estructura de la población 27

4. Reflexiones finales 30

Notas 32 


\section{LA VULNERABILIDAD EN LAS ESTRUCTURAS Y PROCESOS DEMOGRÁFICOS DEL CHACO}

Ana Marí a H. Foschiatti

Los riesgos que surgen en las sociedades a partir de los cambios sociales y demográficos requieren de la capacidad para controlarlos. Esto último depende del grado de vulnerabilidad (inseguridad y desprotección) a que está sujeta la población y de las desigualdades económicas (pobreza). Las diferentes conductas demográficas (fecundidad, migración), los índices de dependencia y los procesos demográficos generan situaciones que modifican constantemente los riesgos sociodemográficos a los que se ve expuesta la población.

\section{La vulnerabilidad asociada a las variables demográficas}

Existen factores de vulnerabilidad relacionados con las características geográficas, económicas e institucionales de las sociedades y para analizarla es necesario conocer las particularidades de la población expuesta al riesgo. Las variables demográficas que estimulan la vulnerabilidad plantean riesgos que provocan un impacto social en los procesos y estructuras demográficas. ${ }^{1}$ Esos componentes del crecimiento como así la estructura han variado constantemente en las diferentes épocas:

1. La fecundidad alta al principio, significó un aporte al crecimiento de la población aunque limitada por los elevados valores de la mortalidad. En la teoría de la transición demográfica la mortalidad y los factores que la provocan implican el cambio de la estructura social. Por lo tanto, si no ocurrieran esas transformaciones tampoco cambiaría la fecundidad. La natalidad en la provincia del Chaco presenta valores altos $y$ muy elevados en las áreas del centro y oeste, mientras que el oriente y sudoeste

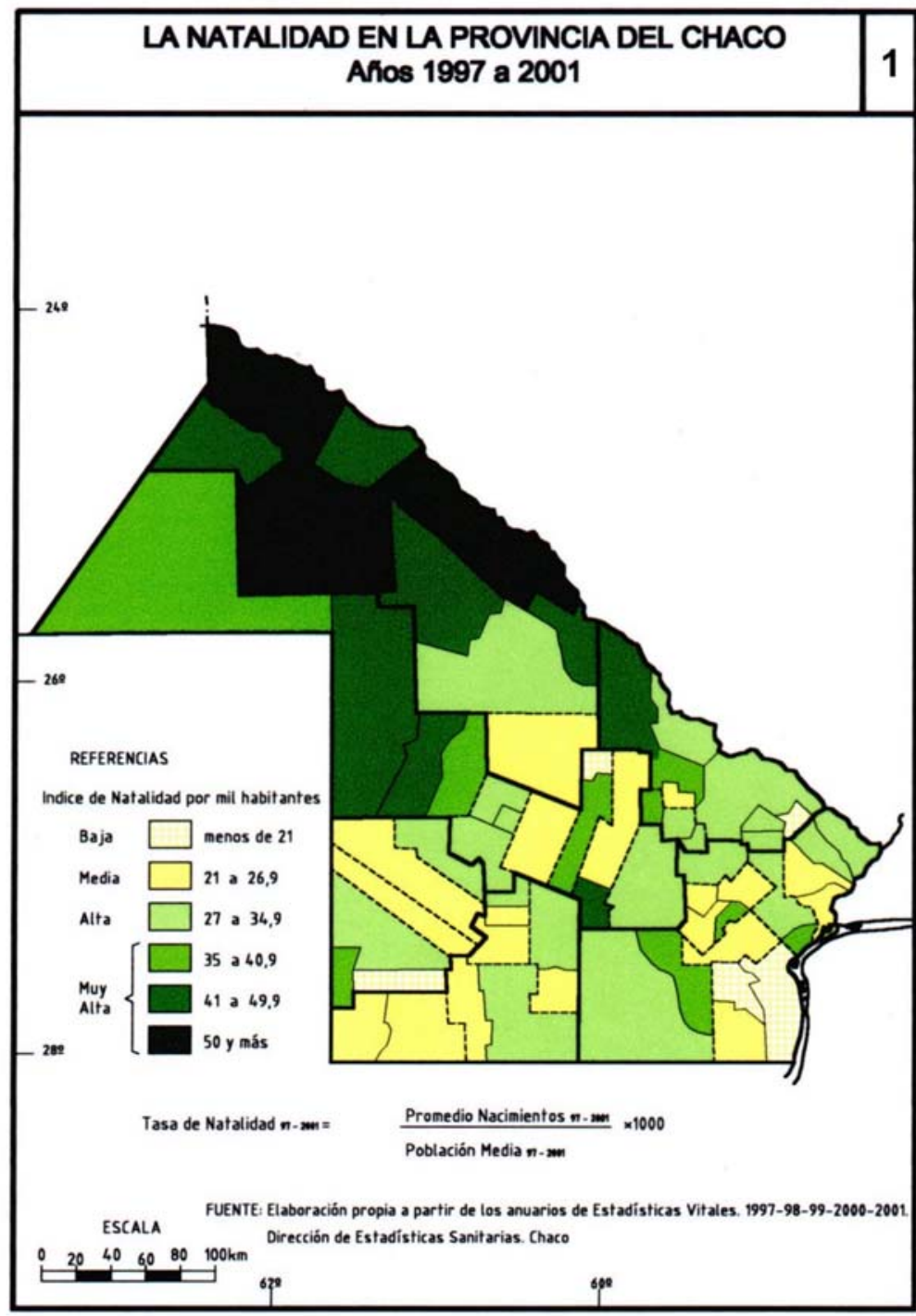




\section{Lavulnerabilidad en lasetruaturasy procesosdemográficosdd Chaco}

tiene valores medios y bajos. De todas maneras, en el largo plazo en las formas en que se organiza la sociedad y la economía, la baja mortalidad produce efectos demográficos tendientes a reducir la fecundidad hasta el presente. La amenaza se observa en la demora en la disminución de la misma en los grupos más pobres y en la maternidad adolescente. La actitud pasiva y la sensación de impotencia aislan a las jóvenes sin educación, pobres y sin asesoramiento ni capacidad para comprender la planificación familiar. Mapa №1.

En el mapa de fecundidad general de la provincia se observa que la misma es alta en las divisiones administrativas del oeste, a la vez que revela una fecundidad global de más de 4 hijos por mujer. Esta caracte-

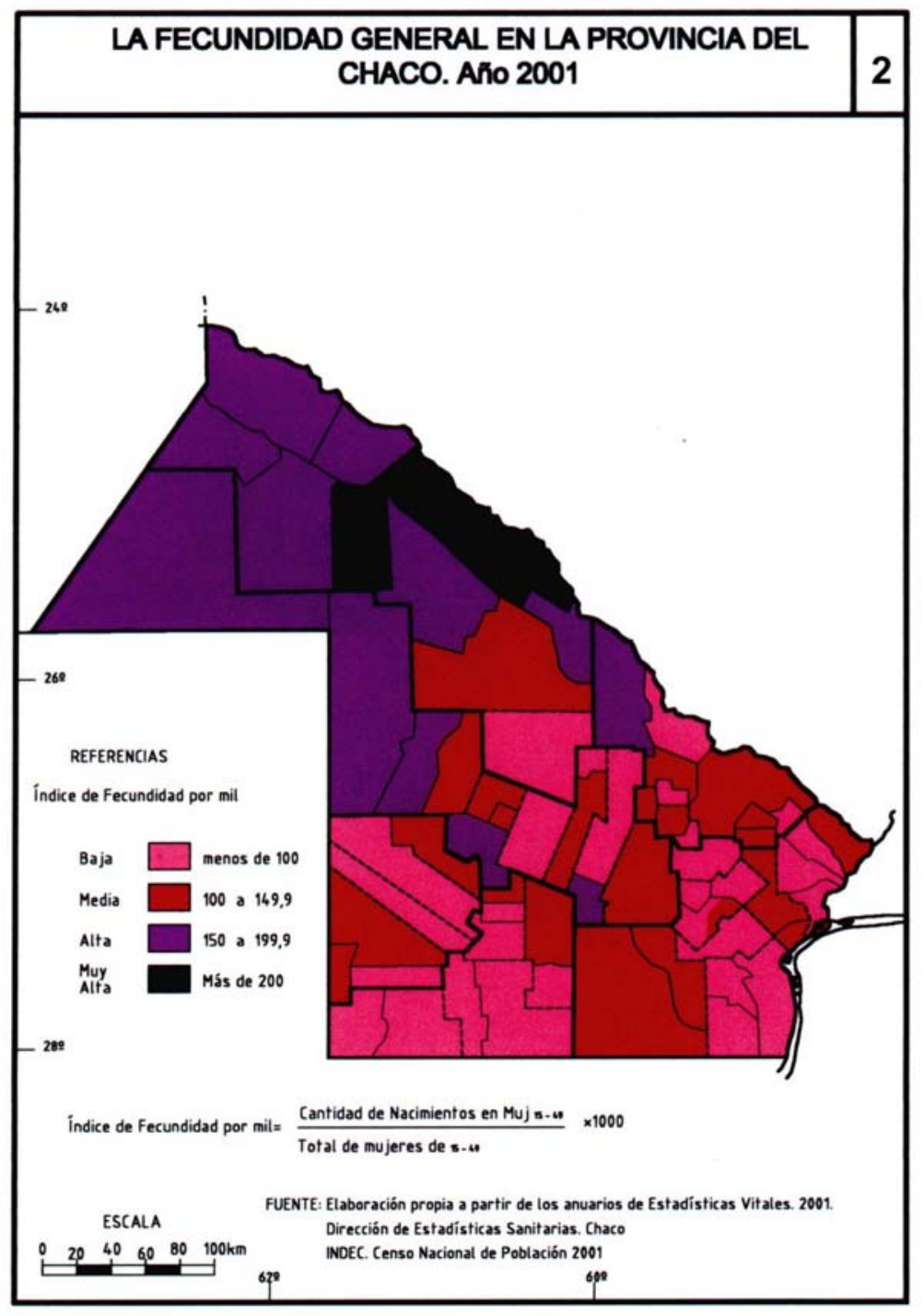
rística se hace extensiva a algunos departamentos del centro provincial. Esa localización se repite en la relación niños/mujeres. Los máximos valores se dan en las mismas jurisdicciones donde la fecundidad es alta, con una proporción de mujeres de 15 a 49 años inferior a 45\%. Mapa № 2.

La fecundidad en la provincia presenta dos sectores bien diferenciados en cuanto a los valores que representa cada área analizada. Tanto la fecundidad general como la global tienen sus máximos en el occidente provincial y no precisamente donde la proporción de mujeres de 15 a 49 años es mayor. Los máximos valores de estos últimos se encuentran en los departamentos con ciudades importantes y más urbanizados aunque con valores inferiores a 100 (baja) de fecundidad general y menos de 2,5 hijos por mujer. Sin embargo las áreas con mayores valores (más de 150 de Fec. Gral. y más de 4 hijos por mujer) se corresponden con la existencia de menos de $45 \%$ de mujeres en edad de procrear. Mapa $\mathrm{N}^{\circ} 3$.

A partir del fracaso de la economía, de la urbanización y de la emigración, se transformó la forma de pensar, en la cual era importante tener una familia numerosa. Sin embargo los grupos menos favorecidos, sin instrucción suelen continuar con comportamientos reproductivos altos y con elevada fecundidad (comienzo de su vida reproductiva a edades más tempranas y mayor frecuencia de los nacimientos) constituyéndose en producto y causa de la pobreza. Comenzar la procreación a una edad precoz restringe a la mujer las perspectivas de realización personal y transmite esa situación a sus hijos convirtiendo la vulnerabilidad individual en una vulnerabilidad social (pobre desarrollo fisiológico, escolaridad incompleta, iniciación sexual precoz, delincuencia y paternidad temprana). 


\section{Lavulnerabilidad en lasetructurasy procesosdemográficosdd Chaco}

2. La morbilidad y la mortalidad han presentado altibajos. Al comienzo las altas tasas se debieron a las malas condiciones de vida de la población, a la falta de políticas de salud, al hacinamiento de las viviendas, a las condiciones insalubres, enfermedades respiratorias y gastrointestinales, entre otras. Posteriormente con la aplicación de legislación en materia de salud pública se introdujeron mejoras en las condiciones sanitarias y, los adelantos en la medicina controlaron notablemente la morbilidad y la mortalidad. A pesar de los logros alcanzados, se puede seguir mejorando especialmente en el área de la mortalidad infantil, indicador sensible del estado de atención de la salud y de las condiciones de vida de la población.

Los indicadores que revelan las diferencias sanitarias son la mortalidad y la morbilidad de la población en los distintos estadios de la vida (infantil, niñez, adolescencia, juventud, adultez y vejez). A pesar de la evidente baja en los valores de mortalidad infantil, la provincia del Chaco posee la tasa más alta del país (26.7 por mil en 2002), seguido de Formosa con 25.5 por mil, Tucumán con 24.3 y Corrientes 23.8.

Los valores de mortalidad tienen estrecha relación con la situación de los pacientes. En el Chaco el $66,5 \%$ de la población carece de cobertura de obra so-

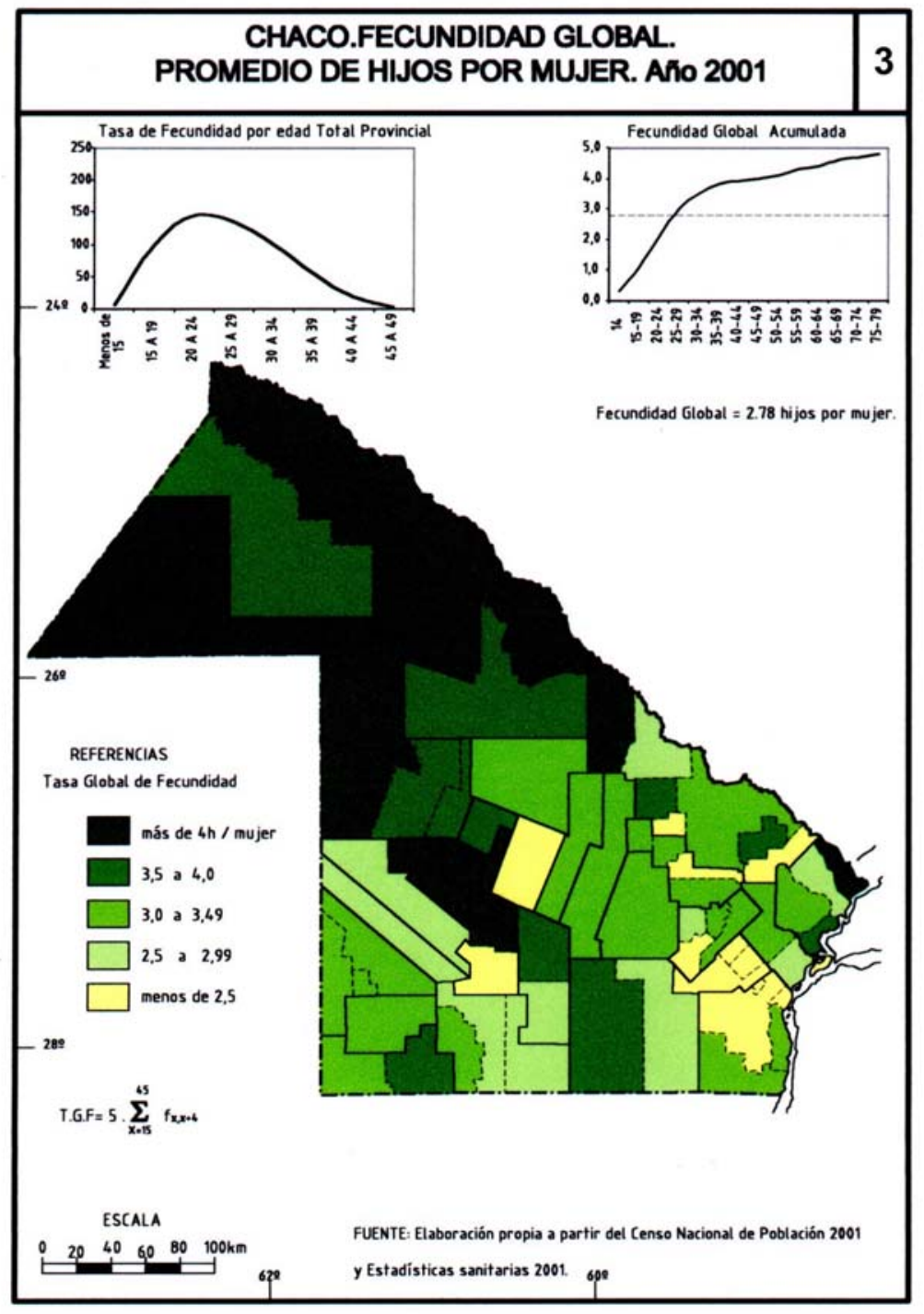
cial o plan de salud y mutual,

llegando en algunas áreas a superar el 75\%. Sólo el 34,5\% posee obra social quedando circunscripta a solo unas pocas áreas del oriente y algunos departamentos con actividades urbanas o rurales de importancia y que les permite contar con ese servicio. Mapa $\mathrm{N}^{\circ} 4$.

3. La migración es un componente muy importante en el crecimiento de la población. La desigualdad en la distribución de los recursos, la pobreza y las políticas de desarrollo aplicadas a la áreas urbanas estimulan la emigración desde las áreas rurales. Generalmente las crisis en la agricultura provocaron el éxodo desde el campo hacia los centros urbanos en busca de trabajo y, ese movimiento produjo profundas consecuencias demográficas (aumento del tamaño de la población distorsionando la estructura por edad y sexo de la población, aumento de las tasas de fecundidad y la densidad de la población) y sociales (condiciones de vida y el mercado de trabajo) en las áreas metropolitanas receptoras y rurales de origen que quedan en situación de vulnerabilidad (formación de asentamientos precarios, aumento del tamaño de los hogares mayor carga de los servicios sociales). Las migraciones entrañan una serie de problemas de integración social y de tolerancia cultural en los lugares de destino. Son movimientos 


\section{Lavulnerabilidad en lasetructurasy procesosdemográficosdd Chaco}

que expresan la inestabilidad, la precariedad y las dificultades que enfrentan muchas sociedades y transforman, a quienes van o vienen, en ciudadanos muy vulnerables.

dos:

Los movimientos migratorios del período 1991-2001 presentan tres sectores diferencia-

El occidente con una tasa positiva de migración

Fi: El oriente en los departamentos capital y aledaños en situación similar a la anterior, donde las áreas urbanas son más atractivas.

Un sector central con un predominio de valores negativos como resultado de la emigración que afectó a la mayoría de los municipios en todo el período, algunos con valores muy importantes en cuento a cantidad de personas que dejaron sus áreas de origen.

La tasa migratoria media intercensal $(3,26$ por mi) con una expulsión de casi 30.000 personas fuera de la provincia, tiene al sector central como al responsable principal de ese total del contingente. Mapa № 5 .

4. Algunos factores de vulnerabilidad respecto de la estructura de la población son la dependencia de los jóvenes y ancianos. La dependencia de estos últimos es importante aunque está bastante lejos del mundo

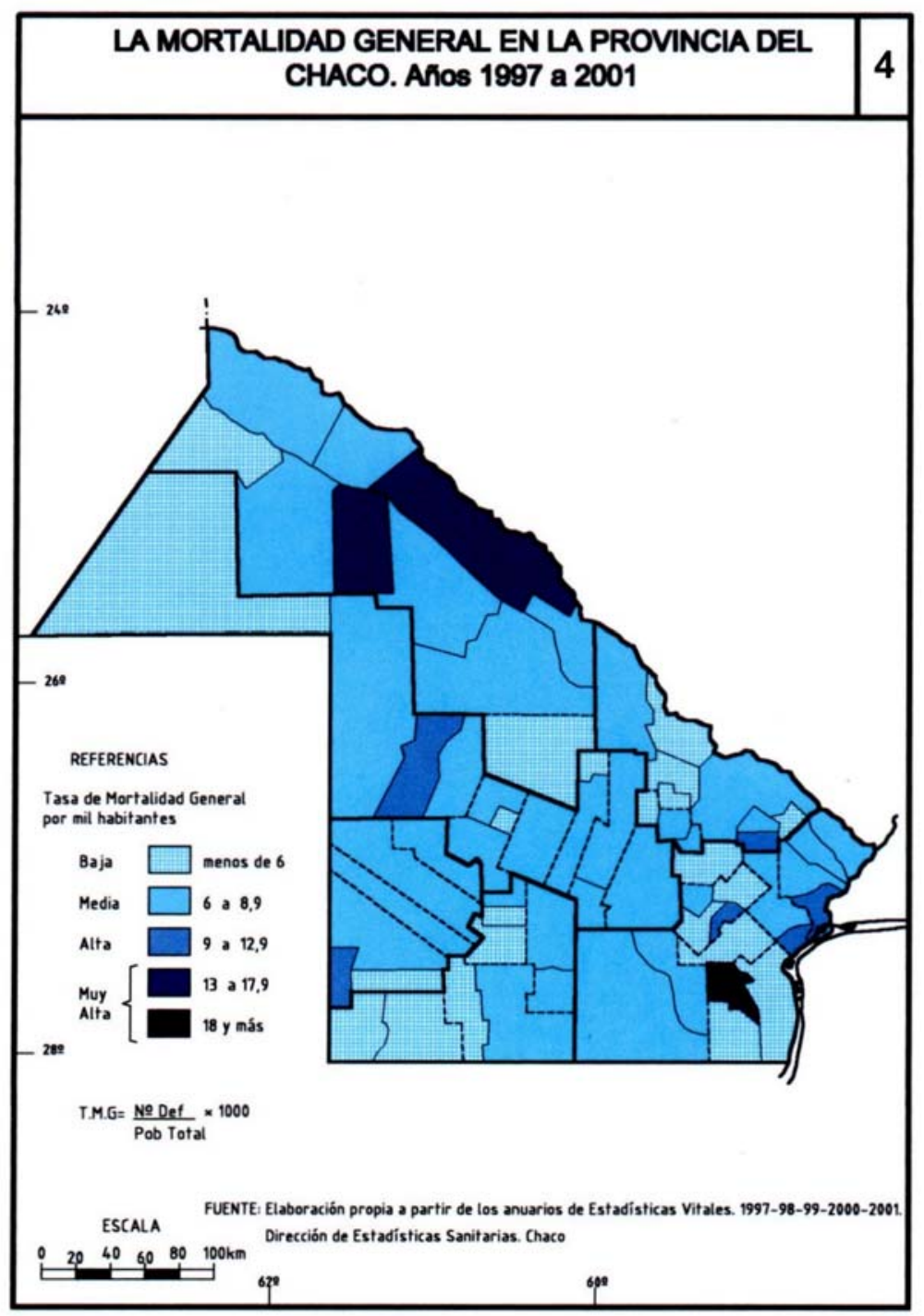
desarrollado que llega a 33\%. La población que se mueve es la que está en edad de trabajar. Demográficamente ese movimiento está asociado al envejecimiento de la población en la comunidad de origen que puede explicar la mayor incidencia, intensidad y gravedad de la pobreza en las áreas rurales. La alta relación de dependencia de los hogares rurales se agrava con la existencia de grandes cantidades de población sin instrucción, hacinadas y con altas tasas de desempleo.

El índice de dependencia que relaciona la carga que representan los jóvenes y ancianos (población no activa) sobre los adultos (PEA) es elevada (73\%). El sector occidental de la provincia expresa una mayor carga de pasivos sobre activos (más de 85\%), principalmente del grupo de jóvenes, dada su estructura piramidal (torre Eiffel). El sector central con una carga entre 80 y $85 \%$ se corresponde con una estructura triangular, mientras que el área oriental con una dependencia menor, con una composición en forma de campana y en algunos casos atípica tiene una carga menor, los valores oscilan entre $60 \%$ y $70 \%$. Mapa $N^{\circ} 6$. 


\section{Lavulnerabilidad en lasetructurasy procesosdemogáficosdd Chaco}

El proceso de envejecimiento plantea riesgos de salud y seguridad social. Por lo tanto es de esperar que ese proceso esté acompañado de una transición epidemiológica con cambios en la incidencia de las enfermedades asociadas a las condiciones ambientales (infecciosas y transmisibles) hacia las endógenas o degenerativas es decir, las enfermedades que se originan en el deterioro de la propia fisiología. Esto se relaciona con la mejora de las condiciones de vida, con la aceptación de otros modos de vida, pero principalmente con la disminución de la fecundidad. Ello hace necesario la disponibilidad y reestructuración de servicios de salud de calidad en función de los requerimientos con costos accesibles, en la tercera y cuarta edad (entre los 60 y 74 años y a partir de los 75 en adelante, respectivamente) aunque la mayoría no está cubierta por obras sociales. ${ }^{2}$

\section{La vulnerabilidad asociada a los procesos demográficos}

\section{2.a. La transición demográfica}

La transición demográfica se caracteriza por el descenso sostenido de la natalidad y la mortalidad desde niveles altos a bajos, lo que se traduce a largo plazo en un cambio poblacio-

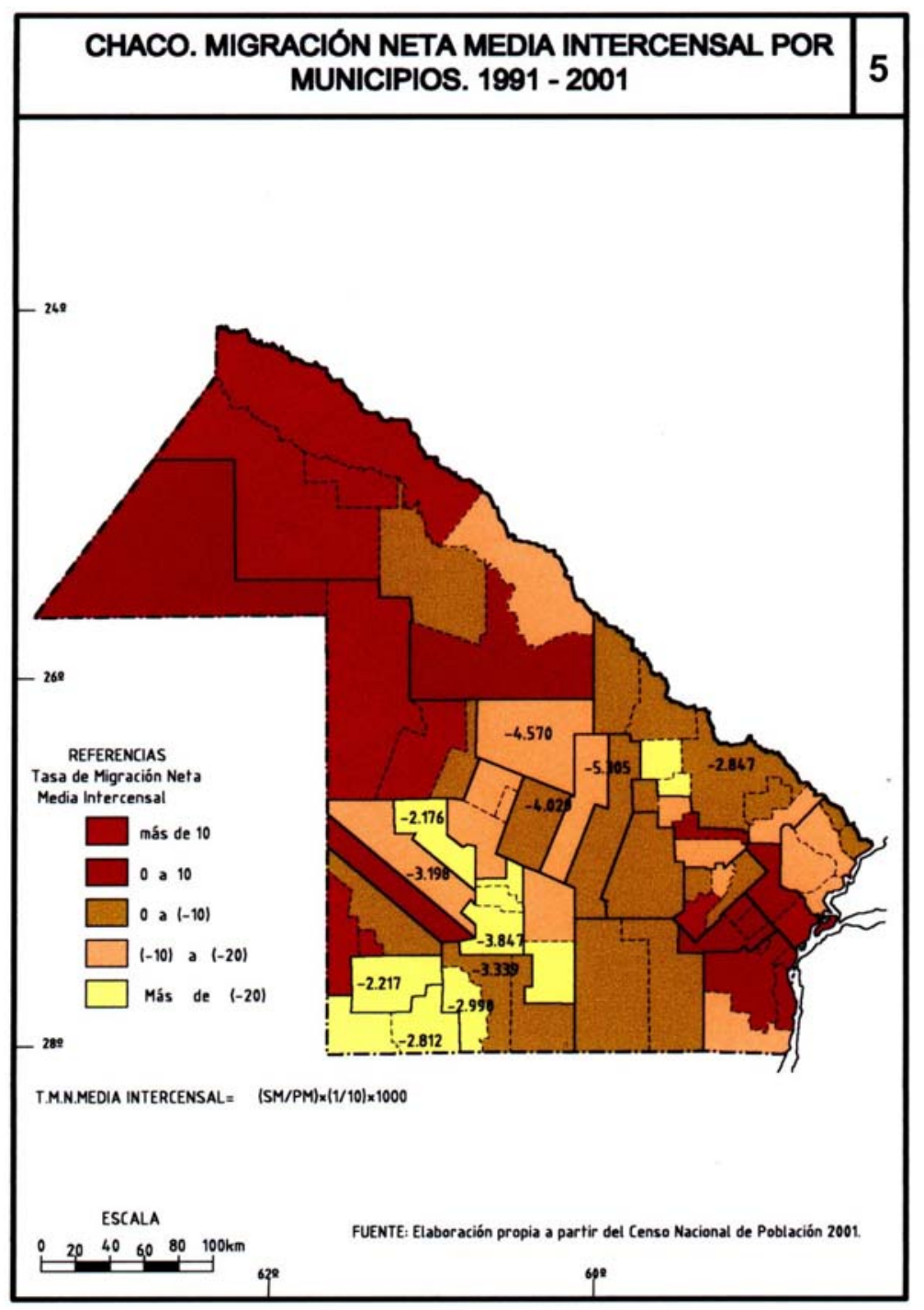
nal que se expresa, al finalizar el proceso, en un lento crecimiento de la población y en una modificación de la estructura etaria (envejecimiento demográfico). Se pueden detectar las siguientes etapas:

La primera etapa, de transición incipiente, se caracteriza por condiciones de pobreza con población predominantemente rural, deficiente acceso a los servicios sociales; con tasas de crecimiento natural del 2.5\%, índices de natalidad y mortalidad elevados y sostenidos y una alta proporción de niños y jóvenes. ${ }^{3}$

En una segunda etapa, de transición moderada, si bien ha disminuido la mortalidad con un leve rejuvenecimiento de la población y un aumento de los índices de dependencia, no se observa el mismo comportamiento en la mayoría de la población rural y en aquellos segmentos sociales en situación de pobreza. Como resultado de una mortalidad en descenso y una natalidad elevada y sostenida se registran tasas de crecimiento natural cercanas al 3\% anual. Dado el importante volumen de población infantil y juvenil con respecto a la población total, es probable que se siga presentando una natalidad elevada. 


\section{Lavulnerabilidad en lasetructurasy procesosdemográficosdd Chaco}

En la etapa de plena transición se registra un predominio urbano, una natalidad en descenso y una mortalidad que ha disminuido considerablemente debido a su joven estructura etaria y las campañas de salud realizadas. El crecimiento medio natural de estos sectores es cercano al $2 \%$ anual.

Finalmente, se presenta la etapa de transición avanzada con un grado de urbanización alto, tasas de crecimiento natural medias anuales del orden del $1 \%$, natalidad baja y mortalidad moderada o baja. Algunas áreas se caracterizan por una importante proporción de población anciana, como producto del descenso en los niveles de fecundidad.

En el caso de América Latina, en primer lugar comenzó a descender la mortalidad, con mayor intensidad desde 1930, para disminuir aun más a posteriori de la Segunda Guerra mundial. Alcanzó un promedio de 52 años de $e_{o} y$ una tasa de mortalidad infantil de 127 por mil a mediados del siglo XX. En las décadas siguientes se logró superar los 60 años de $e_{o}(1970)$ y los 70 años (2000) con una tasa de mortalidad infantil de 36 por mil. ${ }^{4}$

La caída de los niveles de fecundidad fue posterior. A mediados del siglo fue de 6 hijos por mujer con tendencia ascendente por efectos del descenso de la mortalidad que exponía a la mujer a quedar embarazada a edades más avanzadas, además de la mejora en las condiciones de

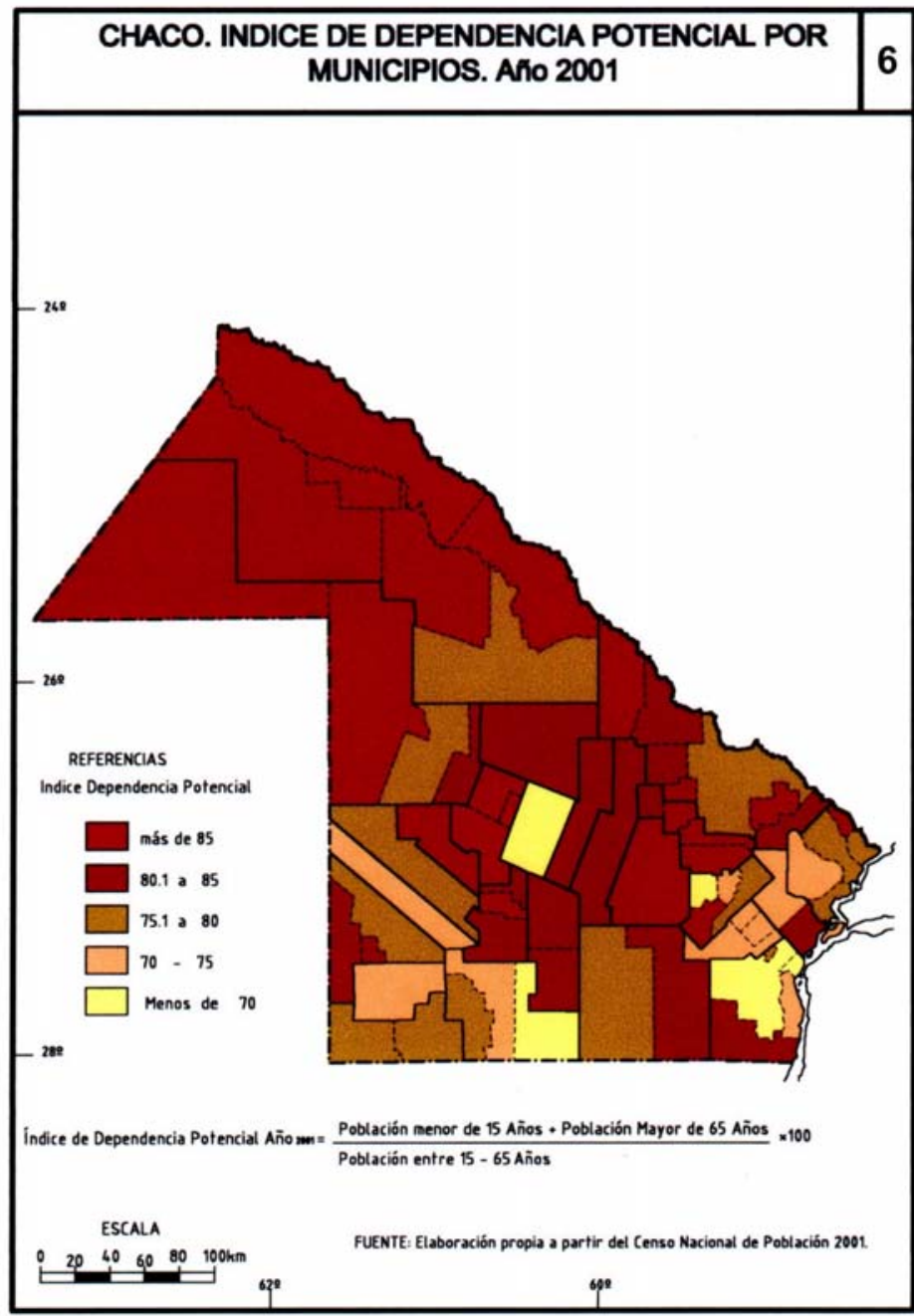
salud.

Gráfico №1: Evolución de la natalidad y la mortalidad en la provincia de Chaco (1911-2001)

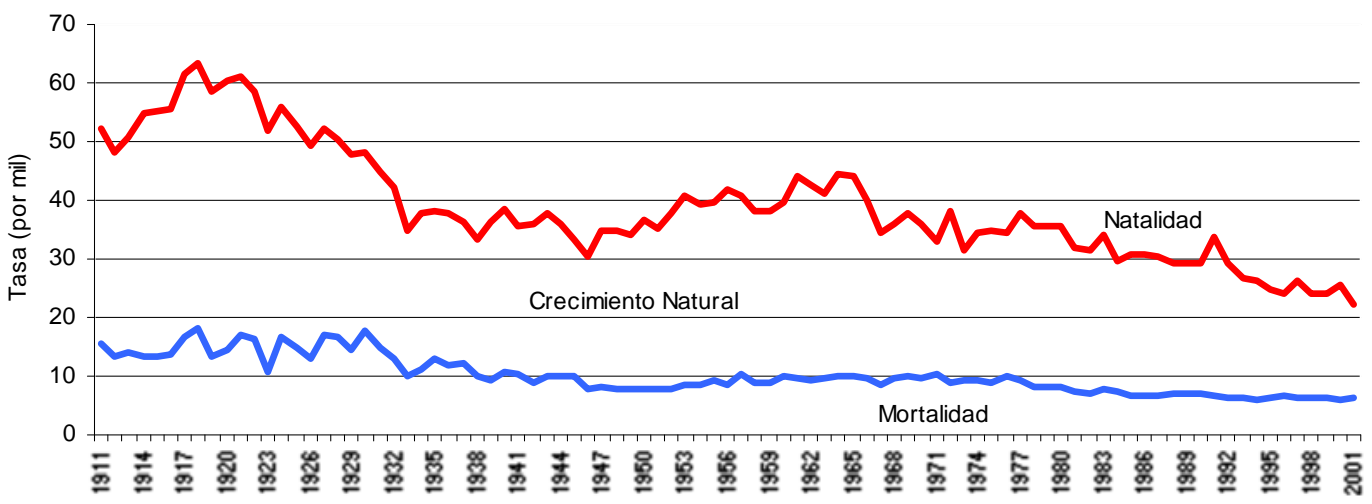




\section{Lavulnerabilidad en lasetructurasy procesosdemográficosdd Chaco}

Recién a partir de 1960 se produce un cambio, llegando actualmente a 2,7 hijos por mujer. Ese cambio es la respuesta a la revolución anticonceptiva que dio comienzo en países europeos con bajas por debajo de los niveles de reemplazo y que luego se extiende al resto del mundo.

En conclusión, la rápida transición demográfica que se experimentó en los países en vías de desarrollo, modifica el perfil que adquieren los riesgos. Desde mediados del siglo XX se produjo el descenso de la fecundidad y de la mortalidad, marcando una disminución del número de niños en los hogares, es decir aumentó el control sobre la salud y la reproducción de las personas, quedando atrás las amenazas de un elevado crecimiento y de una población juvenil altamente vulnerable. Este análisis puede ser completado por tres cuestiones derivadas del mismo: a) con el avance de la transición no se atenúan todos los riesgos (maternidad adolescente) a la vez que emergen otros (envejecimiento), b) existen otros riesgos sociodemográficos

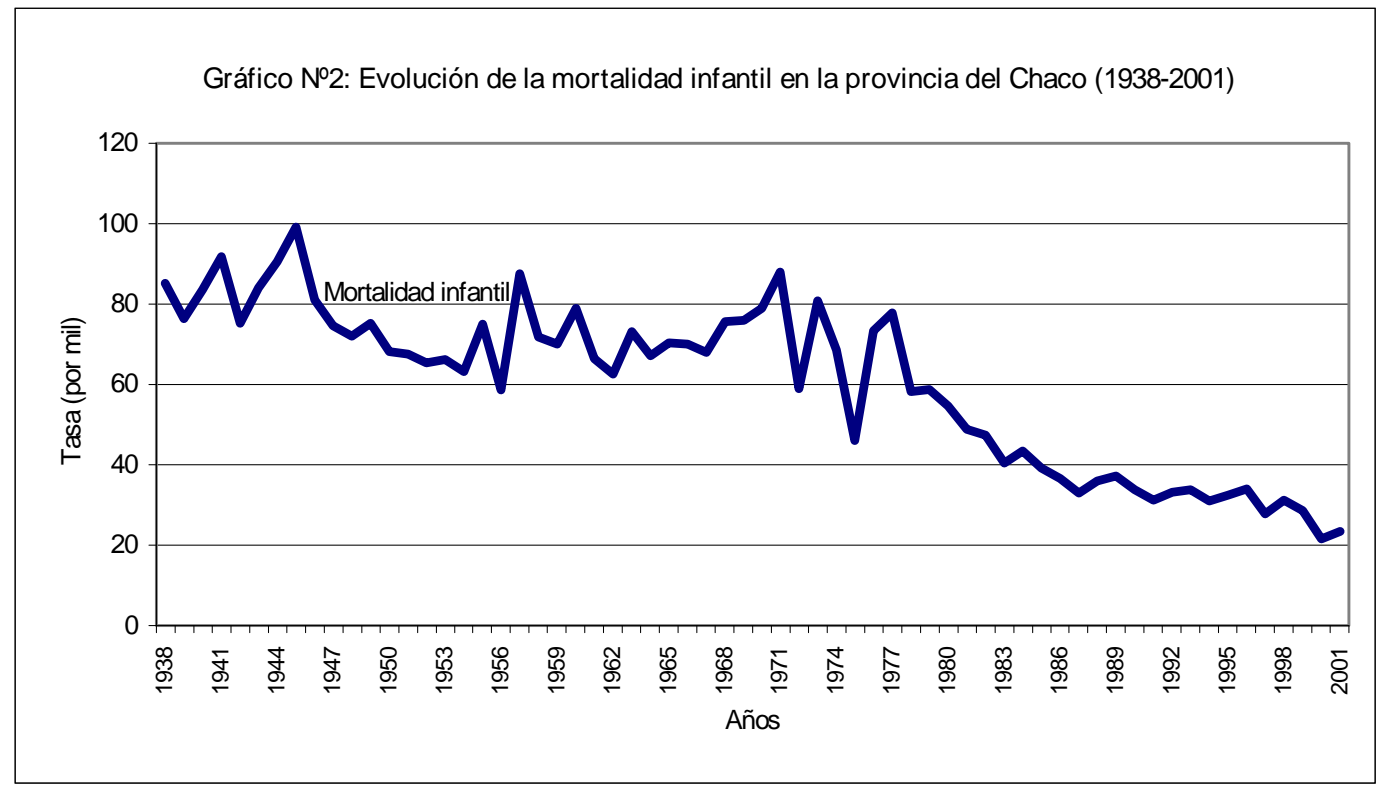

Fuente: Censos nacionales de población.

que dependen de la transición urbana y de la segunda transición, c) el avance de la misma no asegura la disminución de la vulnerabilidad social, pues existen numerosos riesgos que escapan de la esfera demográfica como tampoco se garantiza el logro de aspiraciones sociales y económicas de las personas.

La mortalidad es un riesgo sociodemográfico que se debilita con el avance de la transición demográfica. Ello significa que se pueden evitar muertes por causas previsibles y además, postergar la vida de las personas hasta el límite máximo que permite la capacidad humana y médica. En ese sentido la transición demográfica está estrechamente vinculada con la transición epidemiológica, aunque su avance no es sinónimo de desaparición de riesgos de morbimortalidad evitable, como es fácilmente observable en numerosas áreas y regiones con profundas desigualdades socioeconómicas. La vulnerabilidad no solo se manifiesta en la rápida diversificación de los grupos expuestos, sino en la diversidad socioeconómica que determina la posibilidad de prevenir las enfermedades y en la capacidad de respuesta y adaptación a las mismas.

En ese sentido, la mortalidad y los diversos grados de impedimentos que ocasionan los accidentes y los modos de violencia, no cambian con el avance de la transición demográfica, pues no existe una dependencia con ella. Muchos acontecimientos pueden prevenirse mediante las modificaciones a largo plazo de la conducta y de los factores culturales de los hogares y las personas. Gráfico $\mathrm{N}^{\circ} 3^{\mathrm{a}}$ y 4 . 


\section{Lavulnerabilidad en lasetructurasy procesosdemográficosdd Chaco}

\section{2.b. La transición urbana y de la movilidad}

La transición urbana y de la movilidad se explica por el aumento sostenido de la proporción de población urbana y el estancamiento demográfico de las áreas rurales, que es acompañado por un cambio de las conductas de movilidad (traslado entre las ciudades y dentro de ellas). Por otra parte, la fecundidad, la mortalidad, las migraciones y las complejas interacciones entre población, medio ambiente y organización económica definen los patrones de distribución de la población y la ocupación del territorio. La migración forma parte de la historia de esa ocupación y del comportamiento de las personas cuando no encuentran oportunidades para satisfacer sus necesidades.

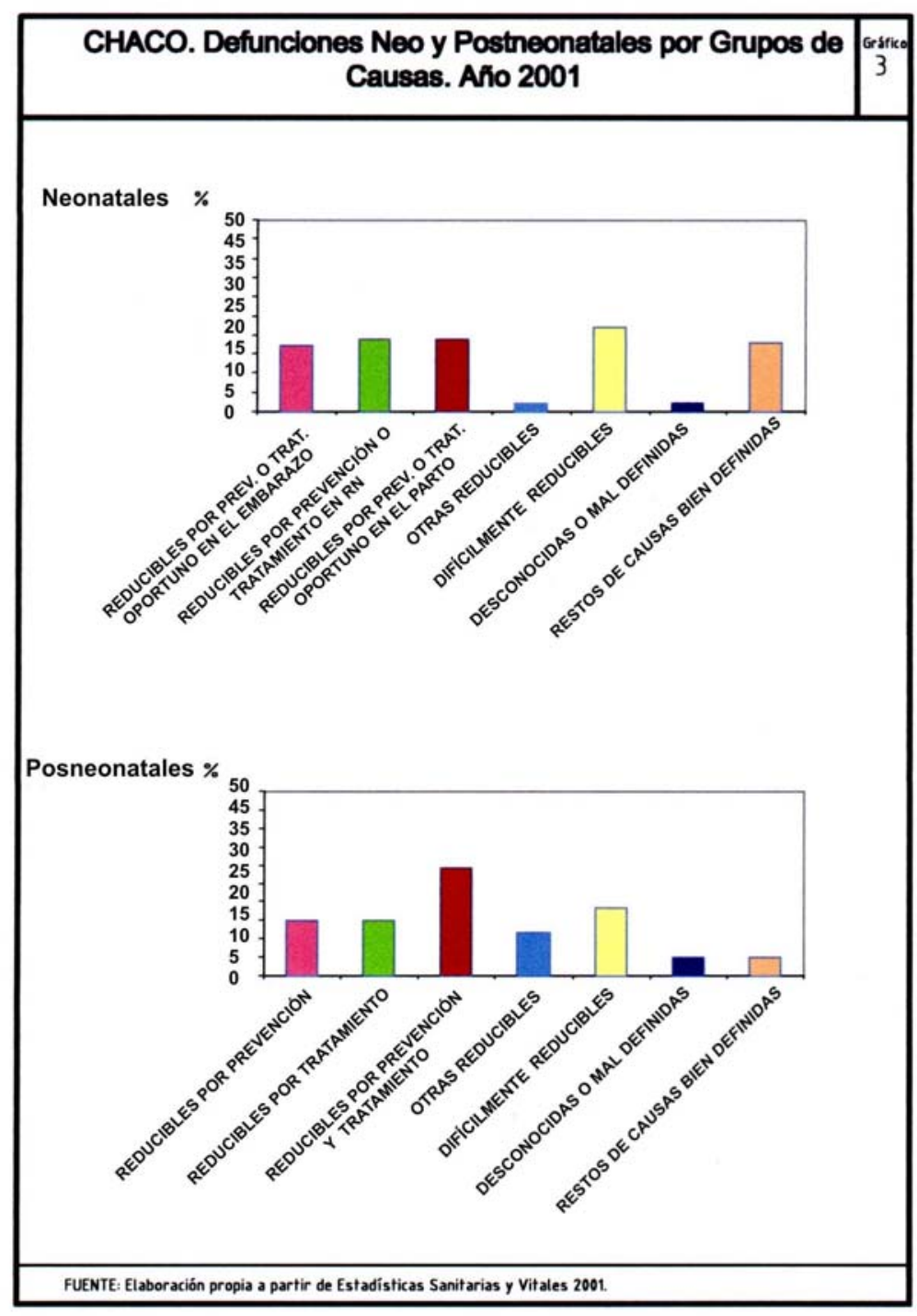

La rápida urbanización y las elevadas proporciones de población viviendo en las ciudades son características inherentes al siglo XX. Por su importancia demográfica, sus causas y sus consecuencias, dicho fenómeno puede ser considerado como un proceso de redistribución espacial. El paso de una situación con predominio rural hacia 1950 a otra con mayoría urbana es una de las más destacadas expresiones de los profundos cambios provocados por la redistribución espacial. A mediados del Siglo XX, en América Latina, la población urbana alcanzaba al $40 \%$, mientras que en la segunda mitad del siglo esta situación consolida a la región como la más urbanizada del mundo con valores que superan el $75 \%$ a pesar de la desaceleración del ritmo de crecimiento de dicha población. ${ }^{5}$ A esta característica no escapa la Argentina donde los niveles de urbanización pasan de $62.2 \%$ en 1947 a $89.3 \%$ en 2001. En el Nordeste los valores ascienden a 29\% en 1947 y $77 \%$ en 2001, mientras que en Chaco las cifras son de $30 \%$ y $83 \%$ respectivamente, acompañando al ritmo del crecimiento en el orden nacional y regional.

Los riesgos que se relacionan con las distintas etapas de la transición urbana y de la movilidad se sintetizan en las ideas de "presión urbana" y "abandono rural". La migración ruralurbana encierra una serie de situaciones desfavorables tanto para las áreas urbanas como 


\section{Lavulnerabilidad en lasetruaturasy procesosdemográficosdd Chaco}

para los propios migrantes que deben soportar situaciones de incertidumbre y de fragilidad en su inserción al medio. Por otra parte el despoblamiento del campo es otro riesgo que se debe enfrentar en las etapas iniciales de la transición urbana, aunque la población rural continúa incrementándose como resultado del crecimiento natural más elevado. En etapas más avanzadas de esa transición se observa que los riesgos y problemas de la sociedad se "urbanizan" a través de la aparición de otros fenómenos como la criminalidad, la contaminación, la violencia, riesgos contingentes que pueden desaparecer. Al mismo tiempo, y en etapas posteriores se pueden promover aspectos positivos como el aumento de la población activa a causa de la selectividad migratoria, aunque la urbanización modifica el perfil de los riesgos sociales, generándose riesgos sociodemográficos como la segregación residencial y el crecimiento desordenado. ${ }^{6}$

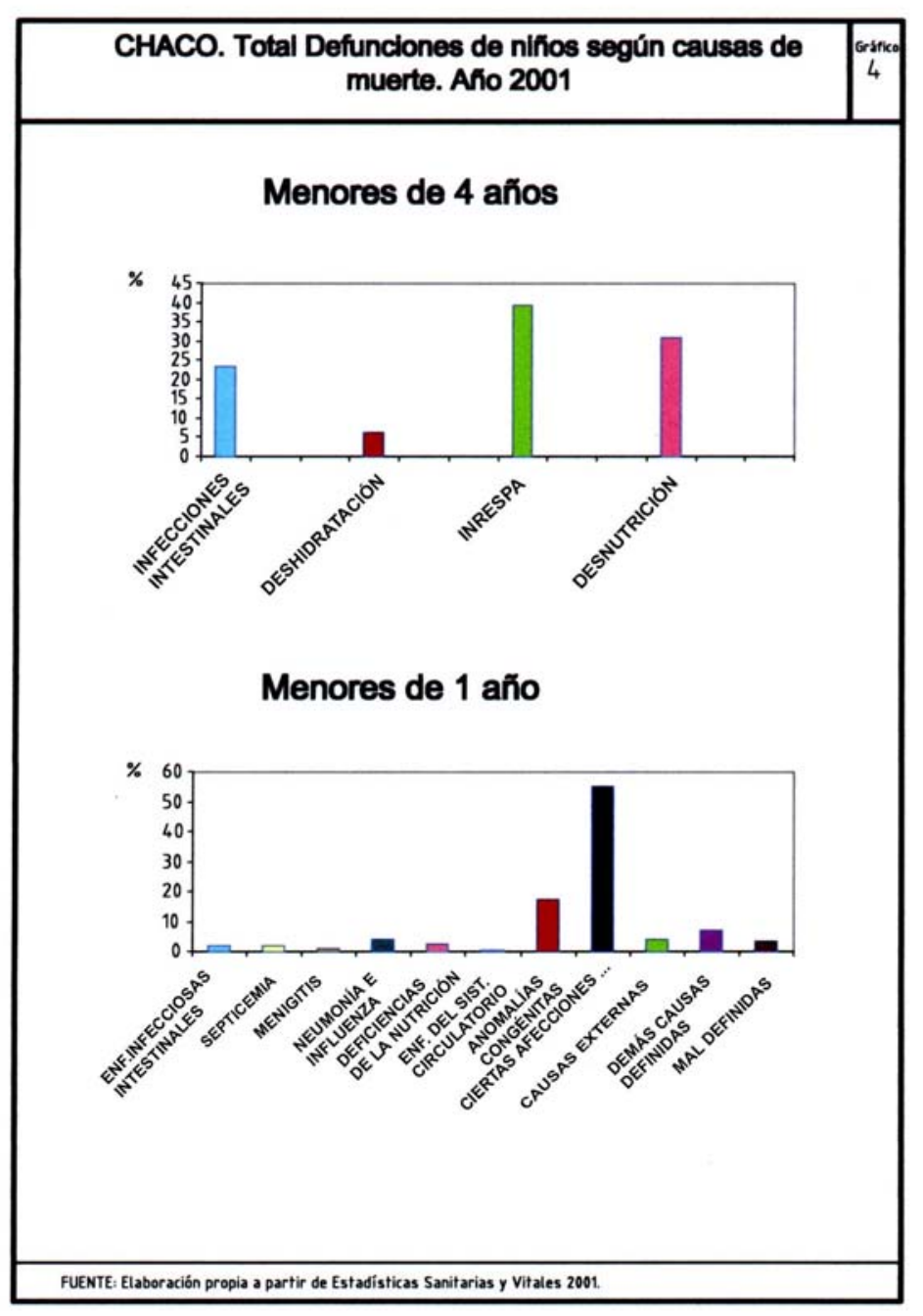

En síntesis, independientemente de la etapa de transición urbana que se trate, la localización de la población conduce a la existencia de dos riesgos fundamentales: la dispersión de la población rural con la proliferación de ciudades de pequeño tamaño y la instalación de las personas en áreas precarias o expuestas a problemas ambientales.

Varios de los riesgos urbanos se vinculan con la organización de los sistemas primados de ciudades o ciudades grandes con predominio de riesgos sociodemográficos relacionados con la localización y la movilidad dentro de las ciudades.

Los procesos de urbanización recientes fueron acompañados de cambios en la estructura interna de los núcleos urbanos y del sistema de ciudades. La mayoría de ellas se estructuran internamente como espacios en permanente cambio donde se oponen áreas centrales colapsadas y periferias recientes segregadas y marginales. Pero al mismo tiempo las grandes áreas urbanas se constituyen en centros de decisión política y económica, de concentración de población, de movilidad, mientras que las de menor tamaño se desenvuelven como núcleos de enlace y difusión de los flujos económicos, hacia el resto del territorio. ${ }^{7}$

En muchos países, el elevado incremento demográfico fue acompañado, por un proceso de redistribución, por una urbanización acelerada y una concentración urbana muy alta. En algunas ocasiones el responsable directo fue el importante crecimiento natural, aunque se asegura que la urbanización tiene en las migraciones rurales, su componente y responsable principal. En ese sentido, el rasgo más sobresaliente de los países subdesarrollados es el peso de la 


\section{Lavulnerabilidad en lasetructurasy procesosdemogáficosdd Chaco}

ciudad de grandes magnitudes, es decir, la supremacía de las capitales en términos cuantitativos. ${ }^{8}$

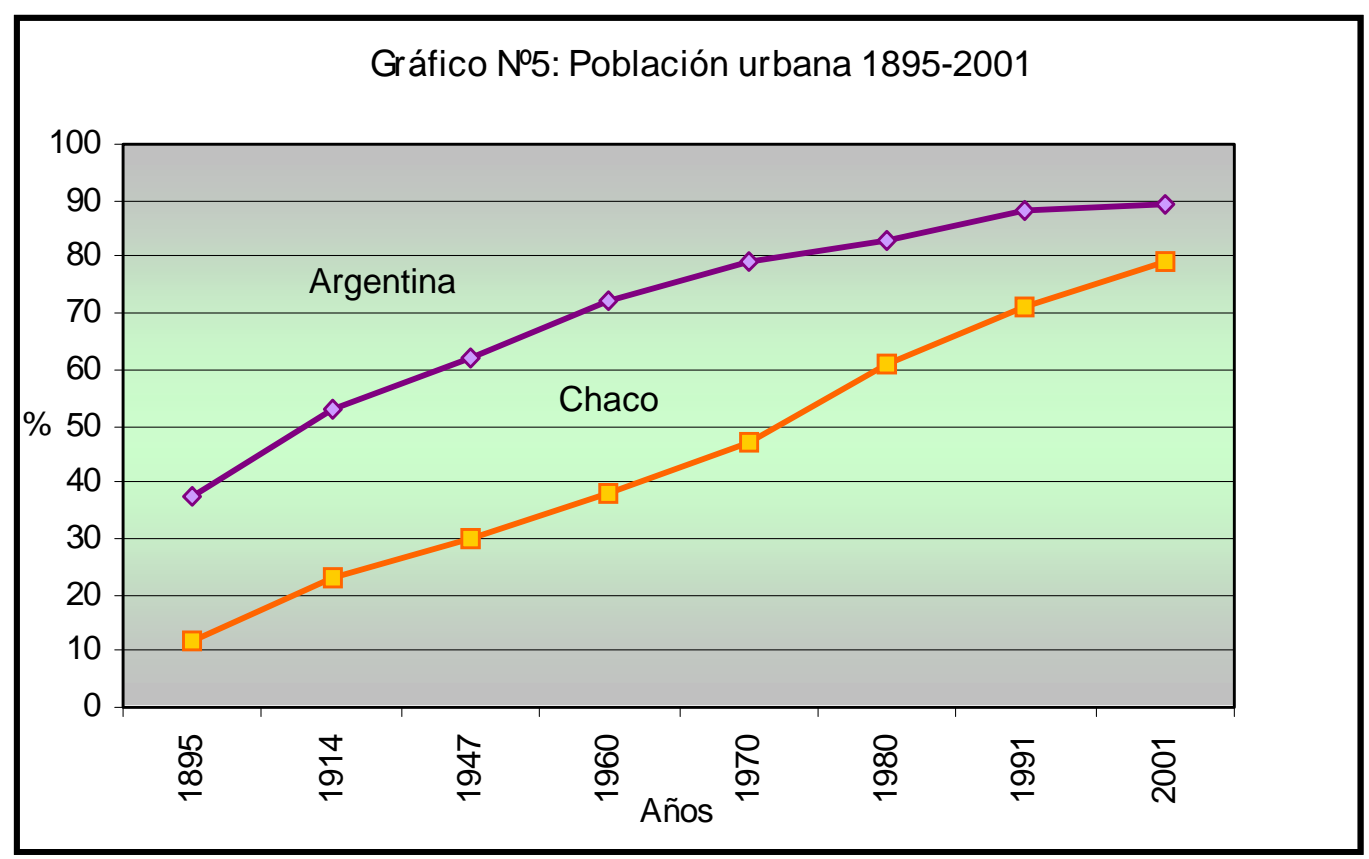

Fuente: Censos nacionales de población

En numerosos sistemas urbanos de América Latina sobresalen las ciudades grandes y su presencia tiene raíces históricas. La vocación urbana de los conquistadores provocó la fundación de ciudades con funciones de defensa y poder político - económico. En el año 2000 el número de ciudades de más de un millón de habitantes alcanzaba a las 49,7 urbes superaban los 5 millones y 4 los 10 millones. Asimismo la evolución de la población de las ciudades fue acelerada y no cabe duda que ellas jugaron un papel importante en el proceso de redistribución

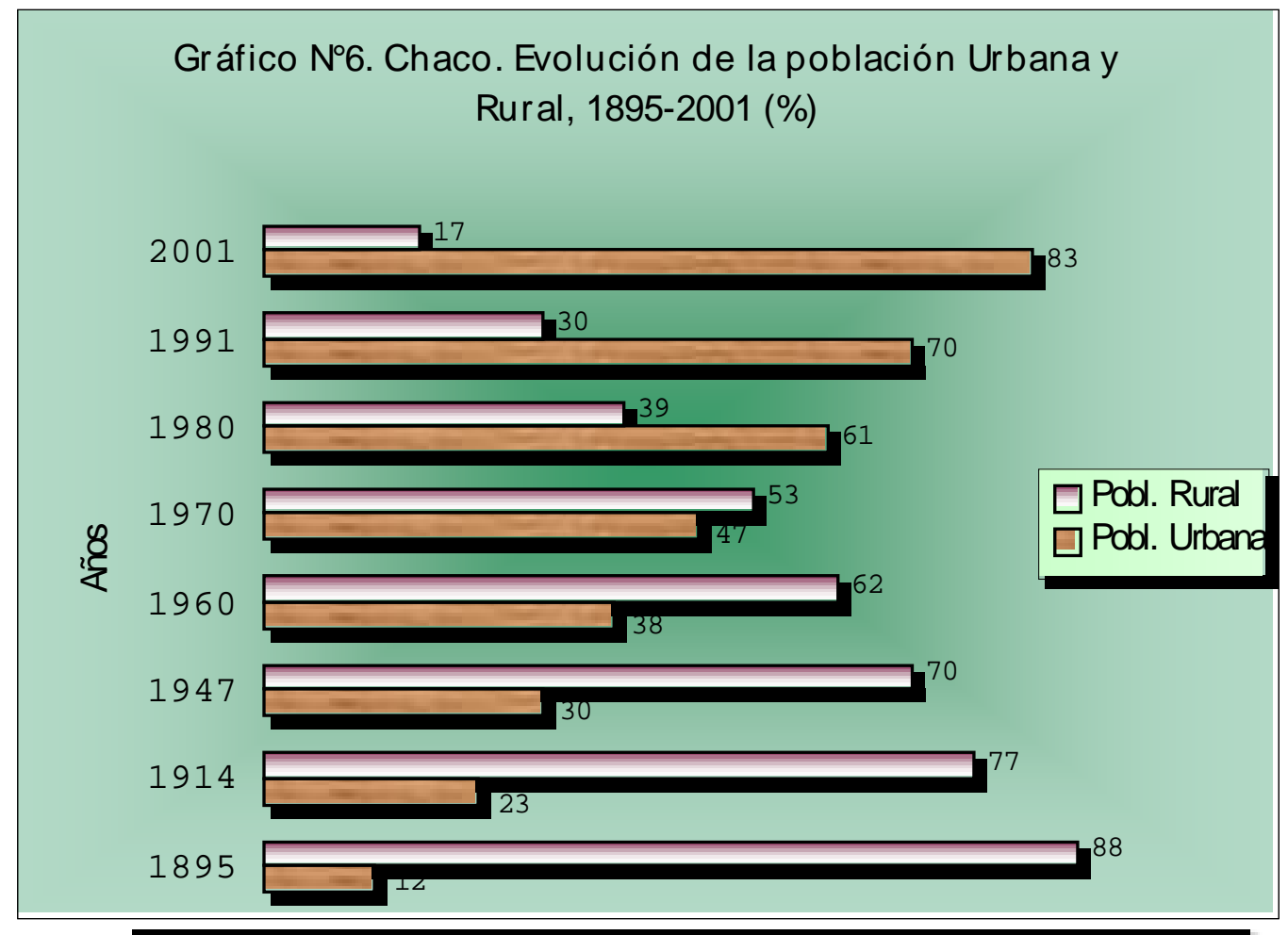

Fuente: Censos nacionales de población 


\section{Lavulnerabilidad en lasectructurasy procesosdenngráficosda Chaco}

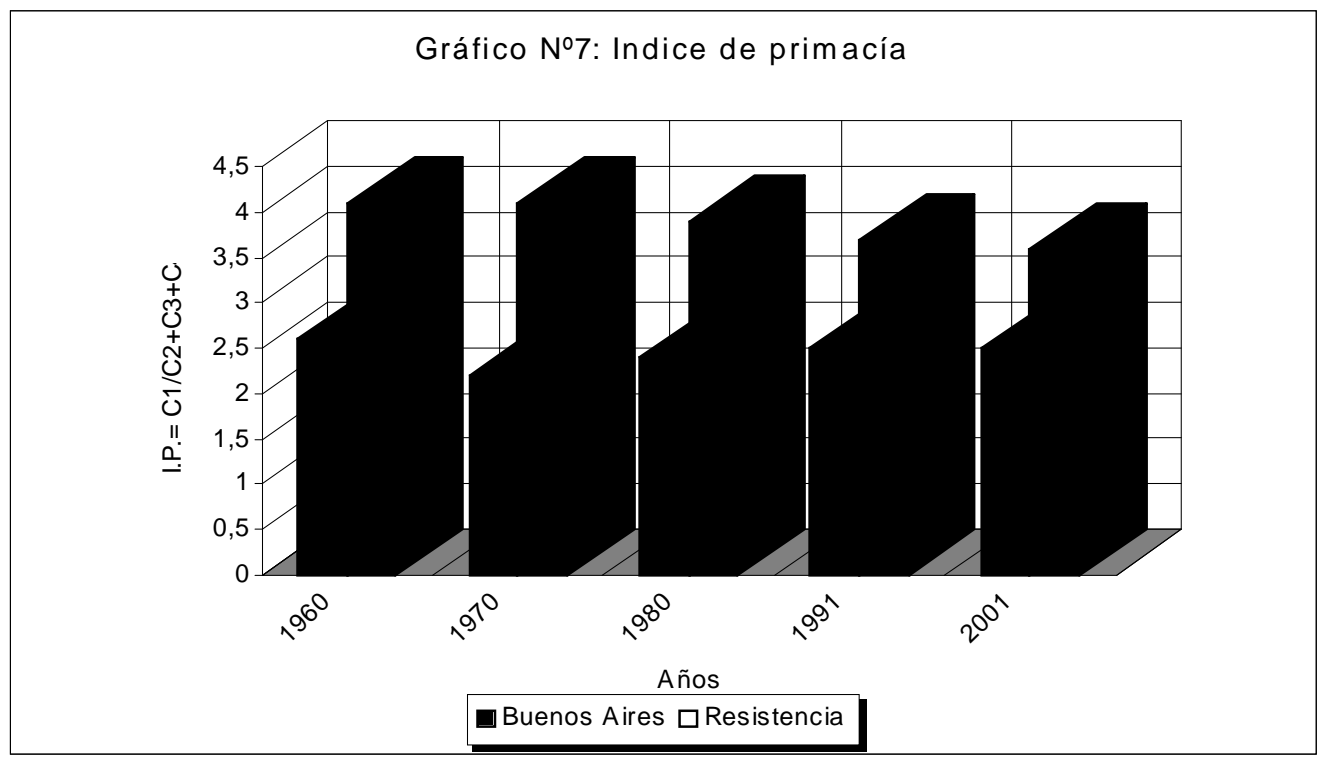

Fuente: Censos nacionales de población

de la población a través de la transferencia de personas del campo a la ciudad por procesos migratorios. La elevada concentración de población en las ciudades principales es un atributo de los sistemas urbanos de los países subdesarrollados (primacía urbana).

El desarrollo urbano en el área se caracteriza hasta 1970 por un alto crecimiento demográfico debido a la alta fecundidad y a la importante migración campo-ciudad, la reclasificación de los espacios rurales y a la tendencia de la concentración de la población en las ciudades grandes. A partir de 1980 se observan algunos cambios debido a la disminución de los niveles de fecundidad y a la reducción de la migración rural, que permitieron la desconcentración de las áreas metropolitanas centrales y el incremento de las ciudades intermedias. ${ }^{10}$

Con una definición imprecisa pues requiere de un sistema urbano de referencia, estas últimas ciudades son uno de los componentes más destacados y dinámicos del sistema urbano

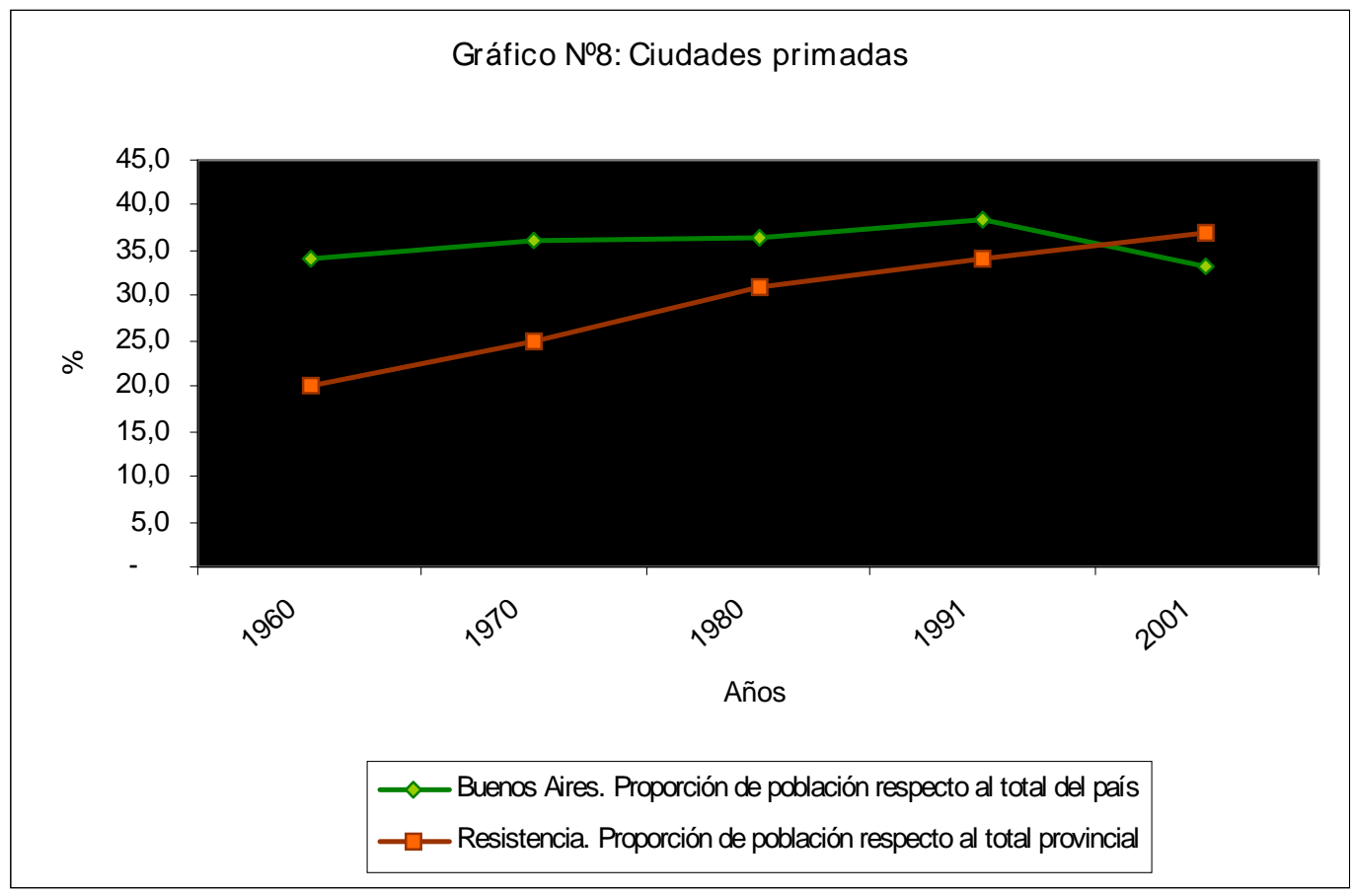




\section{Lavulnerabilidad en lasetructurasy procesosdemográficosdd Chaco}

(entre 50 mil y un millón de habitantes). La cantidad de ciudades y la heterogeneidad de las

mismas dificultan los análisis detallados. Ellas son afectadas muy rápidamente por sucesos puntuales como inundaciones, instalación o cierre de industrias, flujos migratorios. En la Argentina y en Chaco en particular ese fenómeno se observa con suma claridad. Mapas № 7

Resistencia, la capital de la provincia, alcanza a los 361.118 habitantes (2001), aunque se erige en la capital regional más importante y junto a la vecina ciudad de Corrientes forman un núcleo que supera las 500.000 personas. Le sigue en importancia la ciudad de Pcia. R. Saenz Peña que solo alcanza a un $21 \%$ de la población capitalina, un verdadero desequilibrio urbano, más aún si consideramos el resto del sistema.

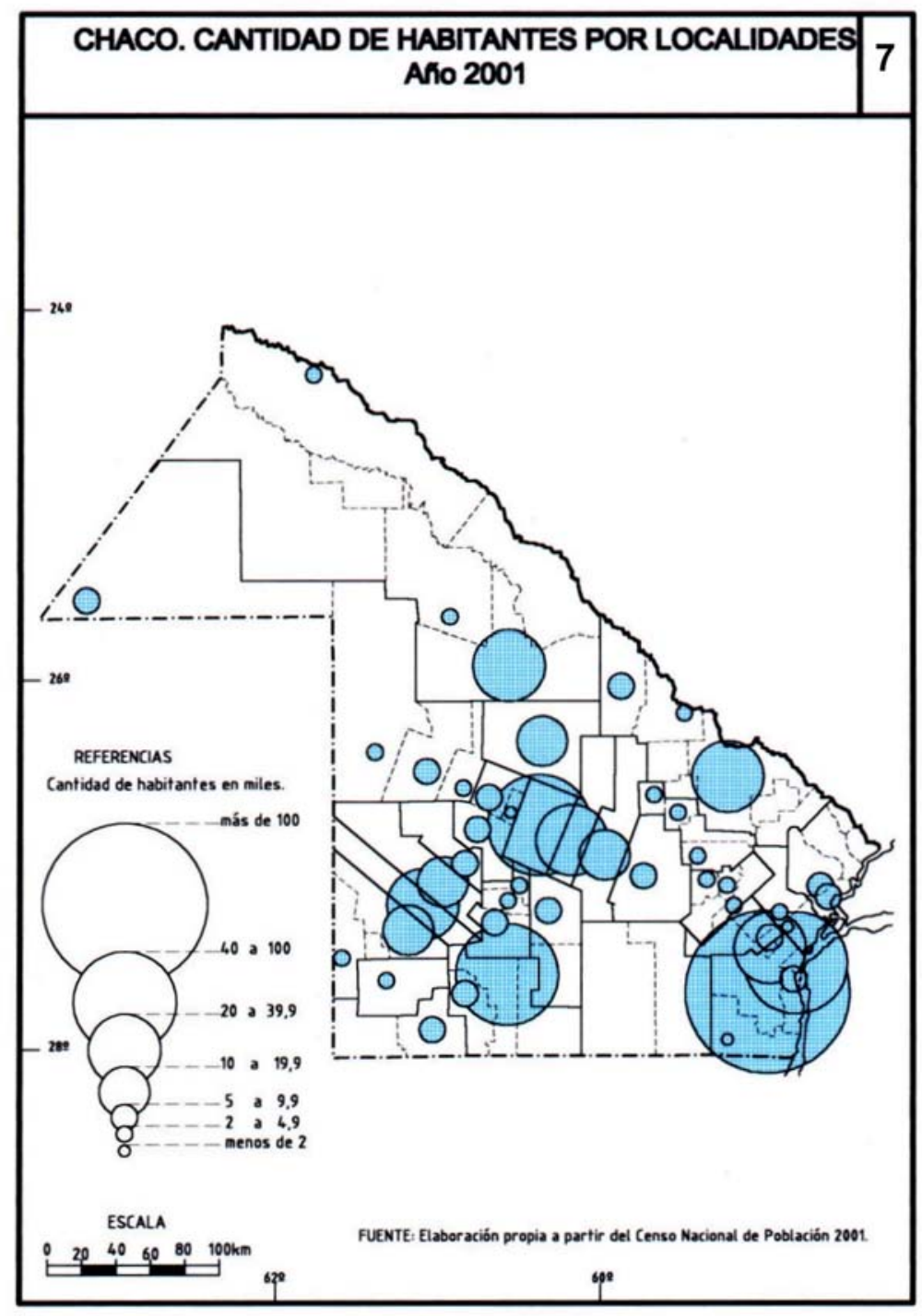

especie de colonialismo interno, y dirigen la vida de la provincia.
La representación gráfica de la regla de Zipf permite expresar los modelos de distribución jerárquica dentro de los sistemas urbanos y su grado de adecuación a la distribución ideal o esperada que se plantea como la situación óptima. Los diagramas resultantes que expresan la situación, muestran un notorio desequilibrio entre los valores observados y los esperados, de acuerdo al modelo aplicado. ${ }^{11} \mathrm{De}$ todas maneras la distribución ideal de la regla expresa las condiciones óptimas que debería tener la jerarquía urbana para facilitar las relaciones entre las ciudades, base El análisis de las redes urbanas y de la organización interna de las ciudades permite concluir que la primacía urbana es el factor desencadenante de los desequilibrios espaciales. Además en el fenómeno del macrocefalismo se acentúa el papel hegemónico de las ciudades que ejercer una

Existe la opinión que cuanto mayores son las ciudades, atraen un considerable número de población en un proceso de autoalimentación continuada. Ello se explica por las características propias de las grandes ciudades, dadas sus ventajas para la localización de actividades financieras, de servicios y bancarias, etc., generadas y aprovechadas en los conglomerados urbanos. Estos elementos de orden económico junto a los de naturaleza política y sociológica como lo son la maquinaria gubernamental, de los medios de comunicación, la convergencia de 


\section{Lavulnerabilidad en lasetructurasy procesosdenográficosda Chaw}

carreteras, la existencia de los recursos públicos necesarios en salud, educación, etc., determinan que la decisión de los migrantes potenciales se incline por esos grandes conglomerados, colaborando así en la producción de la hiperurbanización.

En otro orden de cosas el despoblamiento de las áreas centrales, la segregación residencial o la ocupación de tierras suburbanas expuestas a todo tipo de riesgos se relacionan con la conectividad y la precariedad de los servicios, entre otros. No es un fenómeno nuevo que el ritmo de crecimiento de las periferias urbanas es mucho más intenso que la zona central. La fuerzas que conducen a esta situación están relacionadas con la saturación del espacio central, el elevado costo de los terrenos o la ocupación paulatina del centro por funciones productivas o comerciales. Pero esa expansión periférica difiere de las características de suburbanización de países desarrollados. Mientras en estos se deja la zona central para la instalación de actividades no residenciales y grupos pobres o segregados y las áreas suburbanas para

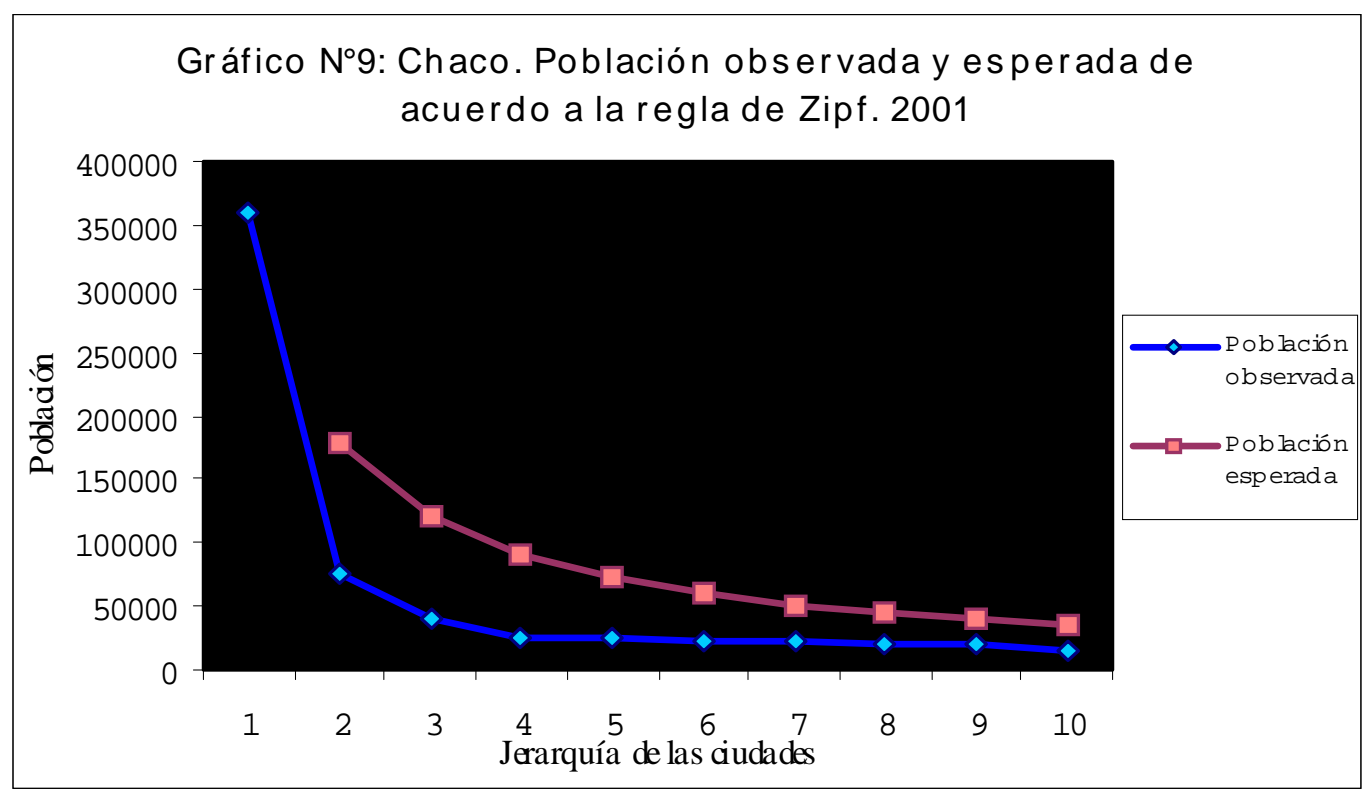

Fuente: Censos nacionales de población

grupos acomodados, en los países latinoamericanos son las periferias ampliadas las que albergan a los más pobres o a los migrantes rurales, que son los responsables de la ampliación de los suburbios. Mapa № 8.

La expansión se debe además a la demanda habitacional insatisfecha (invasiones, asentamientos espontáneos), a la erradicación forzosa de asentamientos, a programas de vivienda construidas donde los terrenos son más baratos, donde se acumulan deficiencias y postergaciones (niveles de vida inferiores a los promedios, equipamiento escaso, deficitaria accesibilidad y precariedad de los transportes, vulnerabilidad ambiental, riesgos naturales, gastos en desplazamientos, etc.).

La radicación precaria es una forma de hábitat generada por las dificultades para acceder a la propiedad de los terrenos urbanos (ocupación informal) en áreas con riesgo ambiental, en terrenos públicos con inseguridad de la tenencia, con déficit de los servicios básicos y riesgo sanitario, entre otros. Una gran proporción de los hogares tiene la combinación de dos factores de vulnerabilidad: un bajo nivel del jefe del hogar y alta dependencia económica, que implica también riesgo para la salud. ${ }^{12}$ Mapa № 9.

El hacinamiento definido como el problema de sobrecarga del parque habitacional causado por el elevado número de habitantes en las viviendas respecto a la cantidad de habitaciones (tres o más personas por cuarto destinado a dormitorio) tiene los peores índices en esos sectores marginales. Es destacable notar que el hacinamiento es un factor que interfiere en la adquisición de capital educativo de las personas y favorece al crecimiento de la pobreza. ${ }^{13}$ El crecimiento de las periferias urbanas es mucho más intenso que la de las áreas centrales, 


\section{Lavulnerabilidad en lasetructurasy procesosdemográficosdd Chaco}

lo que marca un proceso de redistribución de la población a la vez que implica una transformación de carácter social, económico y político de ese ámbito geográfico.

\section{En síntesis:}

泟 A medida que avanzaron la transición urbana y la transición demográfica se transitó hacia una reducción del crecimiento de las ciudades más grandes, aunque estas siguen conteniendo a gran parte de la población total y urbana.

Las mayores aglomeraciones muestran una expansión demográfica importante de las áreas periféricas, mientras las áreas centrales reducen su crecimiento. Ello no se debe a la reducción de la migración rural ni al descenso del crecimiento vegetativo, sino a los procesos de redistribución dentro de las ciudades de magnitud y complejidad crecientes.

Actualmente y en las urbes de mayor tamaño, el proceso de segregación residencial hacia las áreas alejadas es un denominador común, desde finales del siglo XX.

\section{GRAN RESISTENCIA. DENSIDAD EDIFICADA. Año 1991}

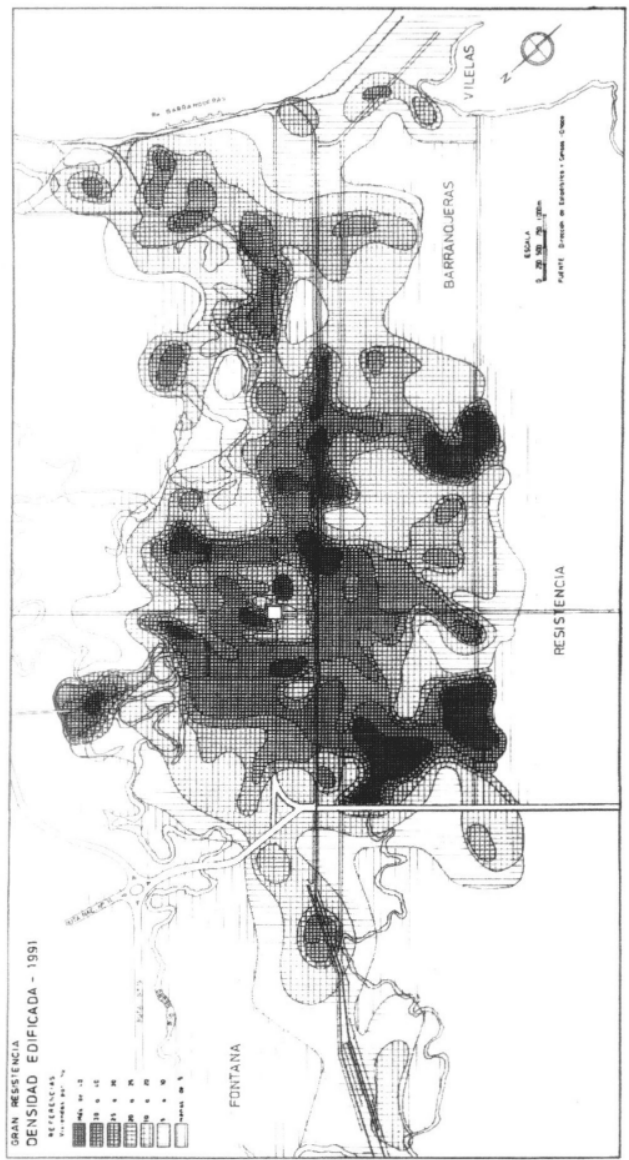

FUENTE: Elaboración propia a partir de Dirección de Estadísticas y Censos.

Ei El proceso de transición urbana conlleva un descenso sostenido de la fecundidad y la mortalidad, aunque en las áreas con una fase incipiente de ese proceso se complica el panorama pues se registran altos niveles de crecimiento demográfico $\mathrm{y}$ rural con un bajo desarrollo socioeconómico.

[⿰⿷匚⿳丨口丨 Los serios problemas de dispersión y aislamiento continúa en las fases más avanzadas de la transición.

\section{2.c. La segun- da transición demo- gráfica}

Los cambios que están ocurriendo en el comportamiento de la fecundidad en los países desarrollados nos introduce a la llamada segunda transición demográfica que implica modificaciones la estructura familiar, la postergación de las iniciaciones nupciales y reproductivas y la transformación de la institución matrimonial (más informal y frágil) acompañado de un au- 


\section{Lavulnerabilidad en lasetructurasy procesosdemográficosdd Chamo}

mento de la edad al casarse, uniones de hecho, procreación extramatrimonial, disoluciones matrimoniales, que ha llevado a que la fecundidad cayera por debajo de los niveles de reemplazo (2,1 Hijos por mujer) y al crecimiento negativo de algunos países. ${ }^{14}$

La llamada segunda transición demográfica ${ }^{15}$ difiere de los otros dos procesos, pues es un fenómeno propio de los países desarrollados, aunque hay indicios parciales de su extensión al resto del mundo, generando riesgos sociodemográficos, asociados a su retraso o a su avance.

La alta fecundidad está asociada generalmente a los sectores con menores ingresos, los más pobres, de bajo nivel de instrucción y radicados en áreas rurales y urbanas margina-

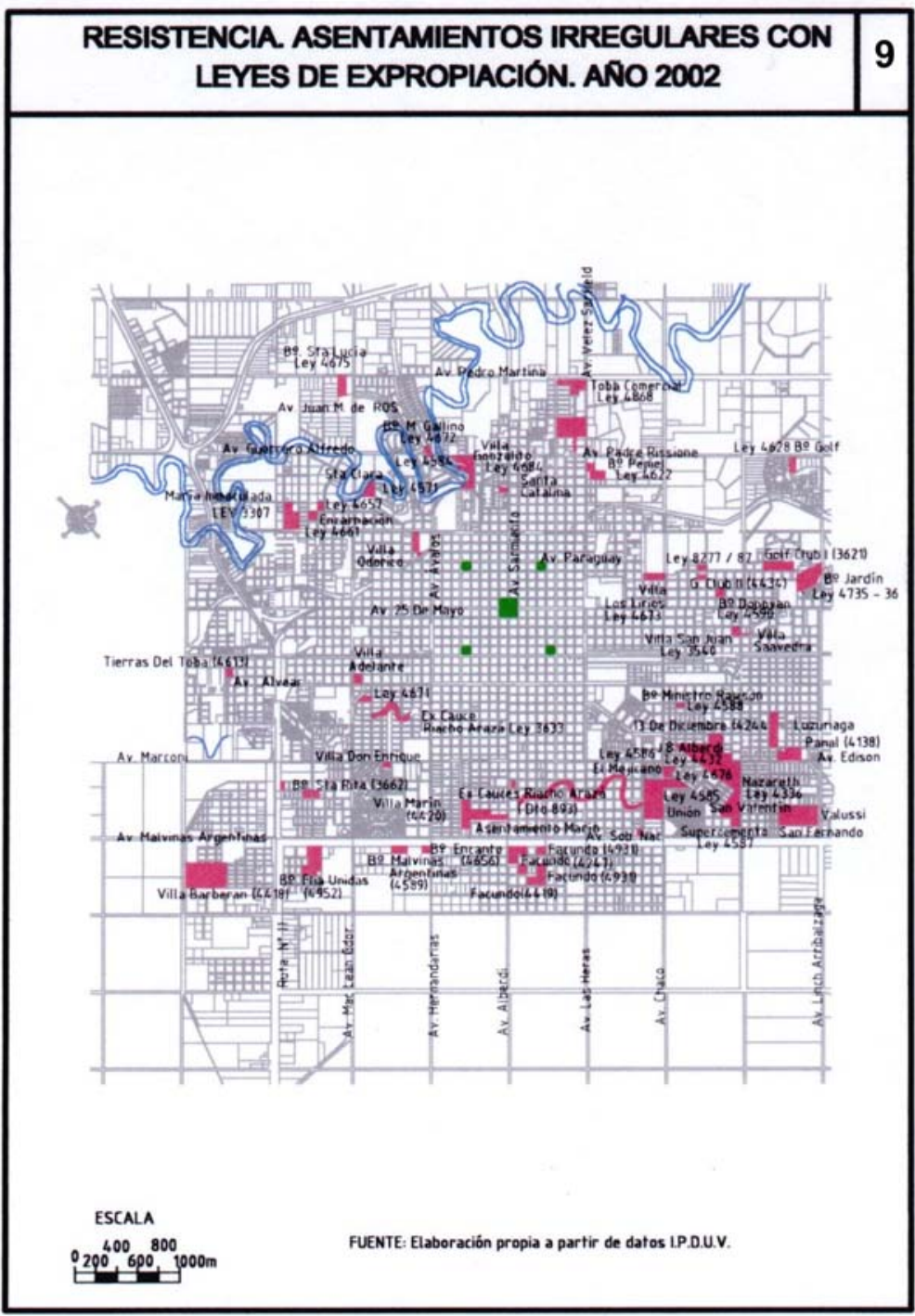
les, entre los que se encuentran los aborígenes; mientras los que han logrado bajar los índices de fecundidad son los más acomodados y los de mayor instrucción, por tener mayor acceso a la información necesaria para planificar los nacimientos y a los medios para controlarlos. El menor número de hijos deseados por las mujeres de condición social más bajo está relacionado con los cambios culturales en cuanto al ideal de hijos, a las condiciones económicas adversas para la crianza y a la incorporación de la idea de familia más pequeña, influencia recibida a través de los medios de difusión. Al mismo tiempo la baja de la fecundidad está relacionada con el aumento del uso de métodos anticonceptivos.

El fenómeno del cambio de los comportamientos matrimoniales y reproductivos, en los países desarrollados muestra índices de fecundidad muy inferiores al nivel de reemplazo (postransición demográfica clásica), incremento de la soltería, los nacimientos fuera del matrimonio, la postergación de las uniones y de la maternidad-paternidad hasta el momento de haber alcanzado un mínimo nivel de formación educativa y de obtener una posición socioeconómica favorable para encarar esas etapas y acontecimientos de la vida. Es por ello que la población joven contrae matrimonio y tiene su primer hijo a edades significativamente mayores que sus pares de los países subdesarrollados. 


\section{Lavulnerabilidad en lasetructurasy procesosdemográficosdd Cham}

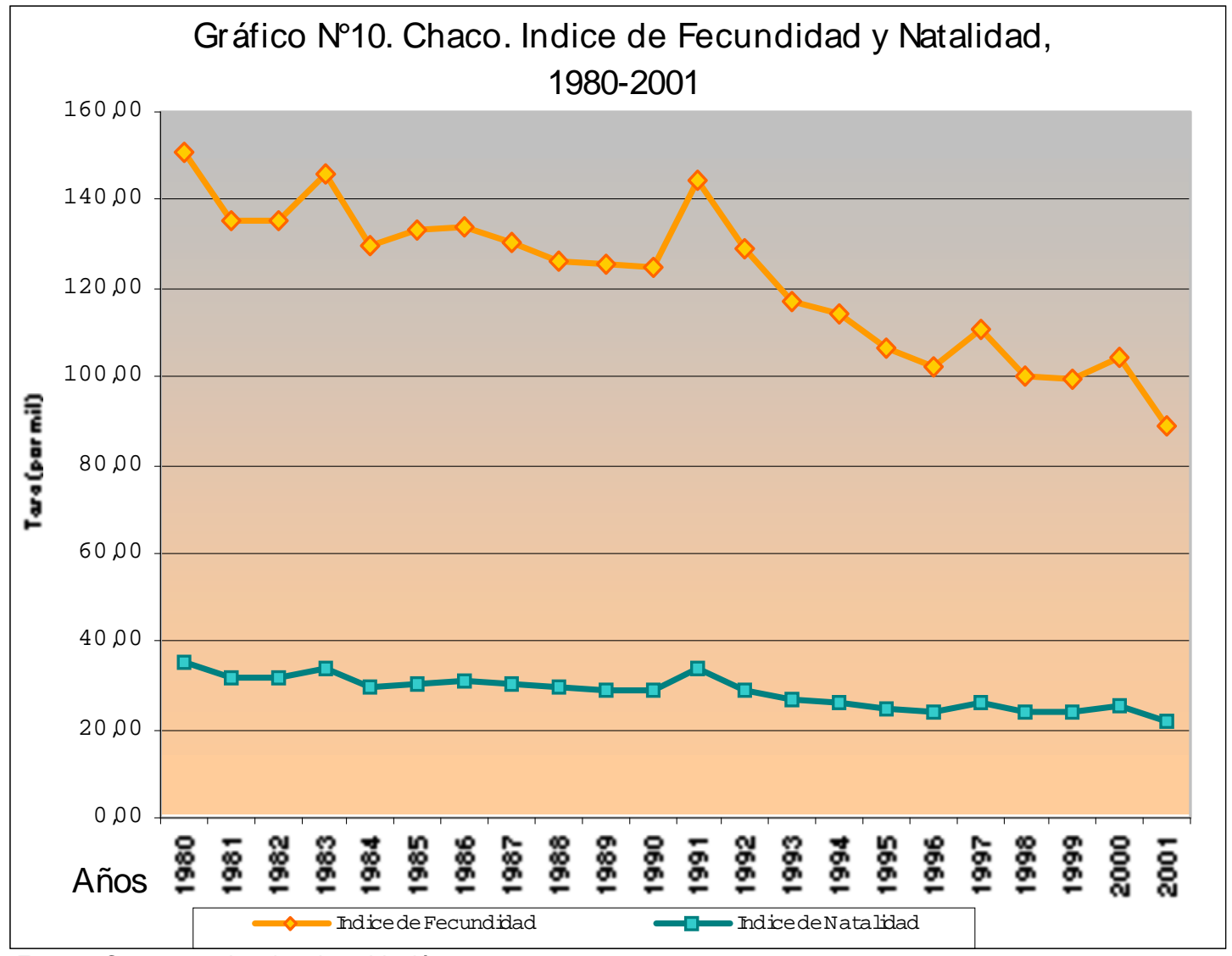

Fuente: Censos nacionales de población, 1980, 1991 y 2001.

Estadísticas vitales, 1980 a 2001

Esto contempla también un aumento de las uniones ilegítimas, de los divorcios, separaciones, que implica dificultades en la crianza de los hijos, el abandono de la mujer propio de esos acontecimientos traumáticos, caracterizados además por cambios socioeconómicos y de

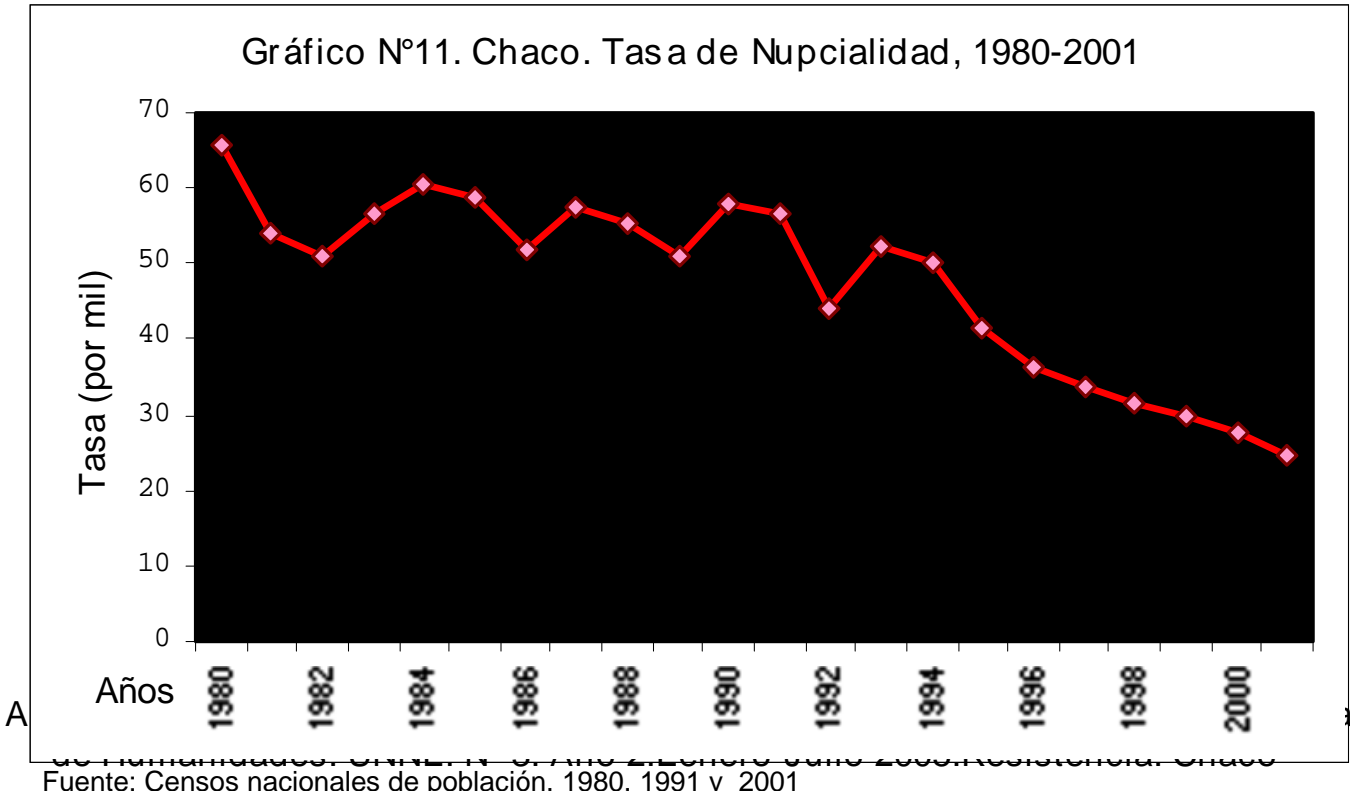




\section{Lavulnerabilidad en lasetructurasy procesosdemográficosdd Chaco}

género, que afectan a hogares con menor capacidad de respuesta o mayor vulnerabilidad frente a esas adversidades. Cualquiera sea el ámbito que se trate, la inestabilidad familiar genera problemas para los involucrados los que requieren aumentar su capacidad de respuesta frente a la posibilidad de ocurrencia. Tales cambios obedecen a una transformación cultural profunda, en la que la individualidad toma una posición central fundamentada en los valores postmodernos, en la conciencia materialista y en el logro de una mejor calidad de vida.

Las conductas reproductivas de los jóvenes surgen como elementos de vulnerabilidad, pues socialmente su comportamiento induce a un retraso de la nupcialidad, de la reproducción y de la movilidad social, pero culturalmente no se cuentan con los elementos necesarios para consolidarlos (educación, oportunidades de movilidad social, respeto a las normas, etc.). ${ }^{16}$

El tema de la maternidad adolescente tiene consecuencias adversas para las involucradas, pues ellas se ven en la necesidad de asumir roles, improvisar decisiones para los cuales no están preparadas, todo lo cual va en desmedro de la estabilidad familiar y la crianza de los hijos. Además la sociedad sufre la salida del sistema educativo de los recursos humanos que están en pleno proceso de formación. Esa reproducción temprana es un riesgo relevante en numerosas áreas y obedece a patrones de conducta y normas socioculturales que implican distintas condiciones de vulnerabilidad. Esta elevada fecundidad adolescente es un componente demográfico de la pobreza que implica un cuadro de vulnerabilidad, pues ese riesgo afecta a los que poseen menor capacidad de respuesta y defensa.

En la provincia se observan cinco modelos de estructura de fecundidad:

- la cúspide temprana (mayor cantidad de nacimientos en relación al grupo de 20 a 24 años) predomina en el occidente de la provincia y algunos sectores del centro. Ello implica una alta natalidad debido al inicio de la reproducción a edades muy jóvenes.

- La cúspide tardía (25 a 29 años) es la menos difundida y se ubica en el oriente provincial correspondiendose con una natalidad baja.

- La cúspide dilatada (20 a 29 años) predomina en el norte y oriente de la provincia. Presenta una natalidad media.

- La cúspide extensa (15 a 29 años) ocupa amplios sectores del centro y sur provincial. Respecto a la anterior hay un inicio del período reproductivo a edades adolescentes con mayores riesgos aunque la edad límite final es coincidente.

- La cúspide prolongada (20 a 34 años) es la menos difundida en algunas áreas dispersas. Estas dos últimas tienen valores medios y bajos de natalidad debido a la distribución de los nacimientos en un intervalo de edades relativamente extensos. Mapa № 10.

- La educación es la principal herramienta de las sociedades modernas para promover y realzar el capital humano, como así lograr la integración de los jóvenes y adolescentes. Las opciones de movilidad social dependen de la educación recibida y si esta es deficiente opera como un elemento de vulnerabilidad que debilita a los grupos humanos frente a las exigentes condiciones del mundo actual. Pero no solamente se trata de desigualdades en la calidad, sino también en la cobertura y en que la formación educativa se complete. Es destacable el problema de la deserción escolar desde los niveles inferiores (educación básica) hasta los superiores, siendo más acentuado entre los más pobres como resultado de su incorporación temprana a los roles adultos, en particular los vinculados al sostenimiento familiar.

Actualmente, los jóvenes de estratos sociales bajos, tanto urbanos como rurales, están sometidos a procesos de vulnerabilidad debido a varios factores, entre otros:

a. la falta de oferta laboral para personas con escasa instrucción que les garantice la cobertura de los servicios sociales y la estabilidad.

b. La carencia de ofertas educativas de capacitación para adquirir nuevas destrezas o aptitudes. 


\section{Lavulnerabilidad en lasetructurasy procesosdemográficosdd Chaco}

c. La falta de recursos familiares para contener a los jóvenes y proporcionarles alimentación, educación y formación.

d. La estimulación social de la sexualidad temprana que no se condice con la educación y la capacitación para obtener comportamientos reproductivos y de prevención de enfermedades.

e. Aislamiento de los jóvenes urbanos pobres debido a la segregación residencial y a la restricción de los servicios básicos.

Resumiendo,

en las investigaciones llevadas a cabo sobre la vulnerabilidad sociodemográfica se utilizan enfoques centrados en la identificación de las desventajas sociales que ejercen efectos adversos sobre los hogares y las personas. La relación de las variables de población con los daños ambientales, la salud reproductiva, la localización de áreas marginales, los activos, los ingresos permiten examinar riesgos como la alta y temprana fecundidad, los elevados valores de dependencia demográfica, el aislamiento y la dispersión de la población. Así los riesgos de la segunda transición permiten tratar los siguientes ejes temáticos: 1. El ciclo vital de las personas que identifica a tramos de edades con mayor o menor vulnerabilidad (infancia, adolescencia, etapa reproductiva $y$ laboral, adultez, vejez); 2. Los derechos de

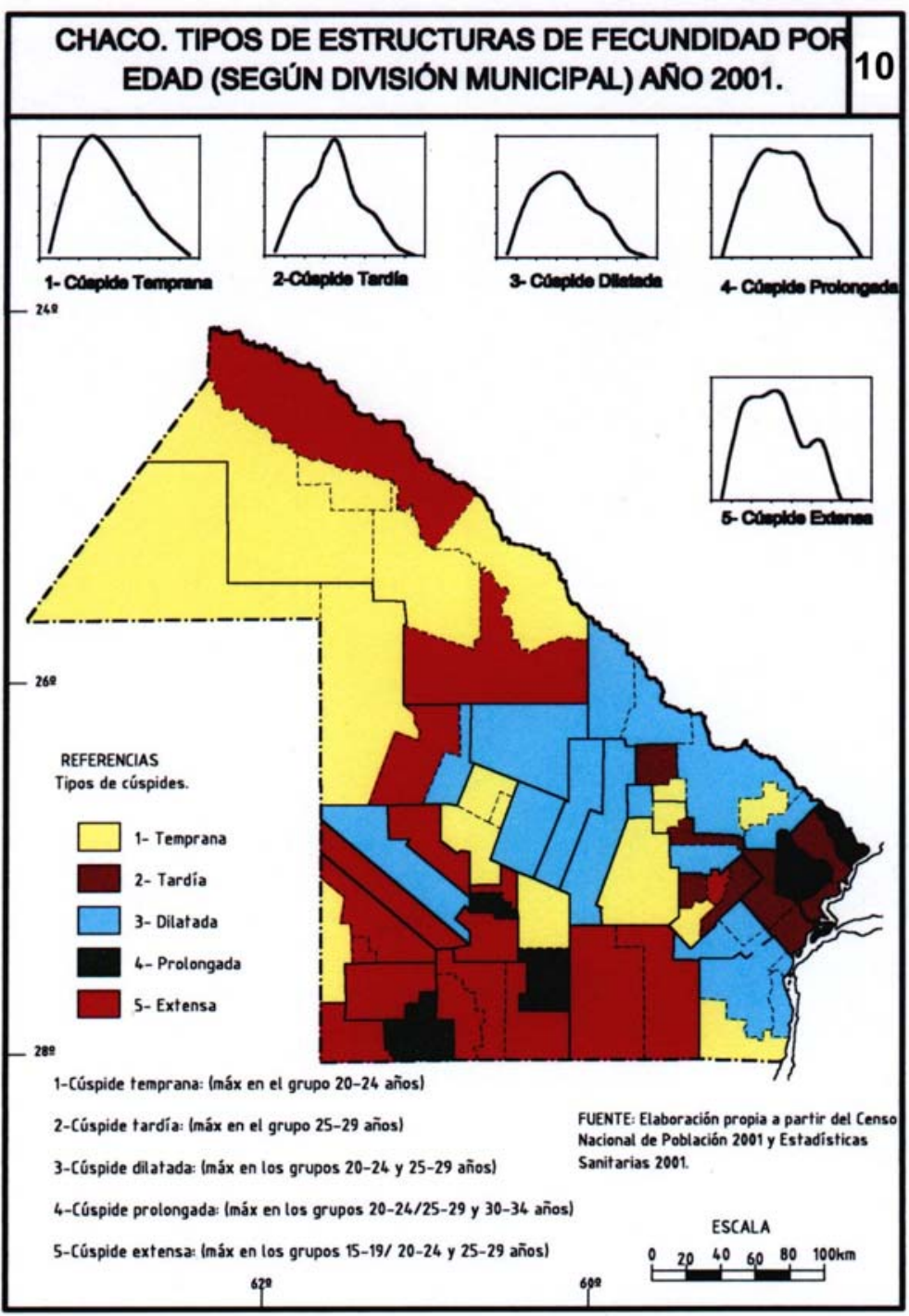
cada una de estas fa-

ses y 3. El estadio de transición demográfica que se relaciona con la segunda transición. Esto permite proponer cuatro indicadores de vulnerabilidad: a) las condiciones socioeconómicas relacionados con la salud de los niños, la educación de las madres, la calidad de las viviendas y los servicios básicos; b) la deserción escolar; c) el trabajo desprotegido y d) la falta de seguridad social. ${ }^{17}$

\section{2.d. La transición epidemiológica}

Los adelantos en la medicina, la mayor cobertura de los servicios de salud y la mejora en las condiciones de vida de la población, produjeron bajas considerables en los niveles de mortalidad. En A. Latina esos cambios se inician en la primera mitad del siglo XX. Según datos proporcionados por Naciones Unidas en los últimos 50 años, se habría ganado 20 años en 


\section{Lavulnerabilidad en lasetructurasy procesosdemográficos de Chaco}

promedio la esperanza de vida, aunque existen diferencias importantes entre los países. En todos ellos la mortalidad femenina es inferior a la masculina asociada a la incidencia diferencial por sexo de las enfermedades o circunstancias que causan las muertes (enfermedades cardiovasculares, violencia). Así la diferencia de esperanza de vida es de 6,5 años a favor de la mujer, aunque se espera que, la mayor participación de la misma en actividades fuera del hogar (que las expone a riesgos similares al de los hombres), como así el combate de enfermedades crónicas masculinas, reduzcan las diferencias. ${ }^{18}$

La mortalidad general de la provincia presenta valores medios, aunque se observan algunos sectores con tasas altas, ubicadas en el occidente. Presenta como primer motivo a las enfermedades del sistema circulatorio (25\%), seguido de los tumores (18\%) y las enfermedades infecciosas (10\%). Si se analizan esas causas por grupo de edad, la primera afecta en un $95 \%$ a los mayores de 45 años y la mitad de ellas a los mayores de 75 años. Lo mismo ocurre con los tumores, enfermedades respiratorias y digestivas, entre otras.

Las muertes provocadas por anomalías congénitas y del período perinatal afectan en su gran mayoría al grupo de 0 a 4 años. Las deficiencias de la nutrición provocan el $33 \%$ de las muertes en menores de 4 años y el $40 \%$ en mayores de 75 años, los dos grupos más vulnerables y con mayores necesidades alimentarias muchas veces difíciles de satisfacer. Las complicaciones del embarazo afectan en mayor medida al grupo mayor de 45 años (66\%) y en segundo lugar al de 25-44 años con el 32\%. Gráfico 12.

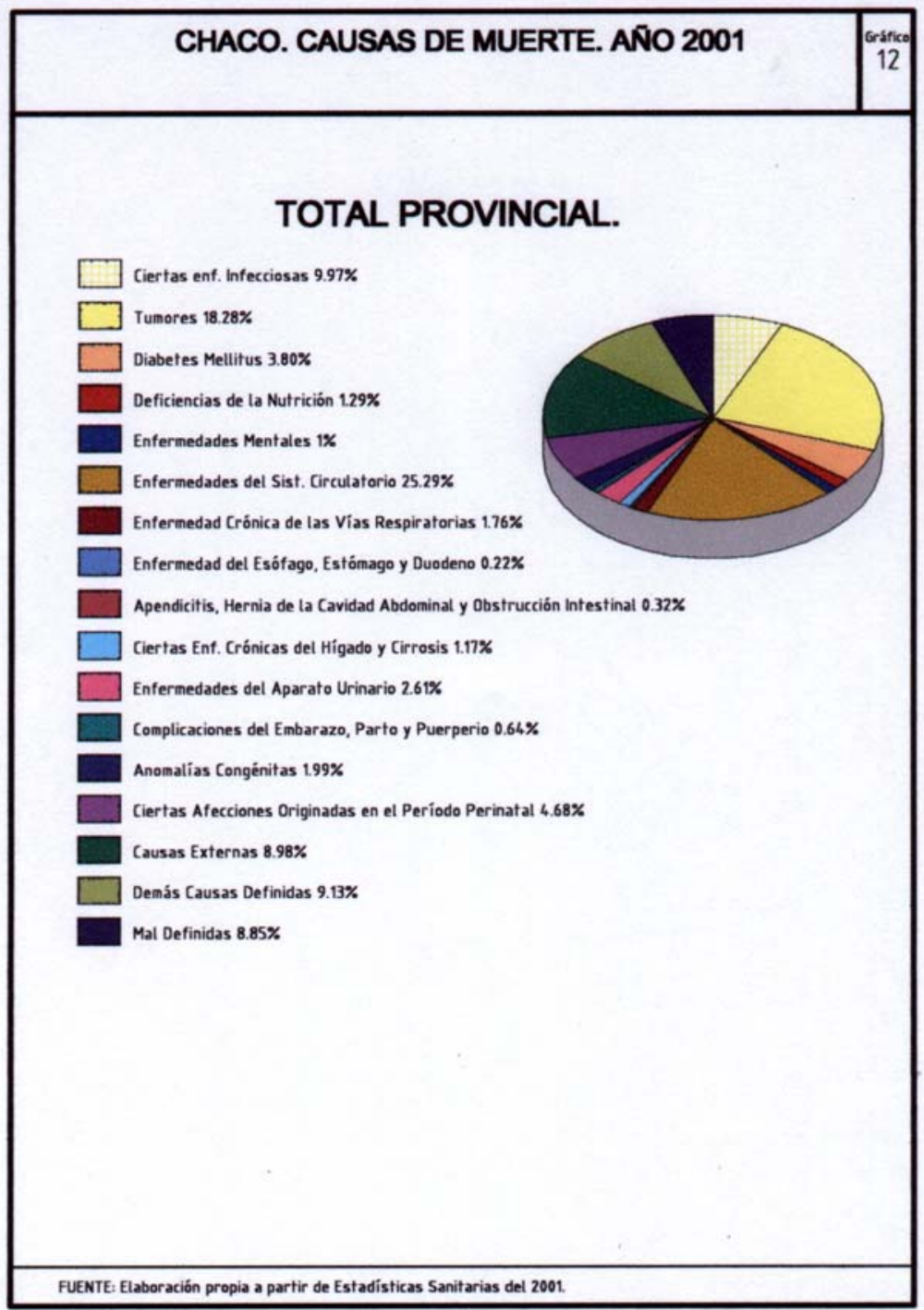

variable importante, porque a ella se asocian distintos riesgos de muerte y la incidencia de ciertas enfermedades. Con el avance del mejoramiento de las condiciones de vida de las personas disminuyen la mortalidad y aumenta la esperanza de vida. Los cambios operados expresan la transición epidemiológica en la estructura de causas de muerte. En la medida que se controla la elevada mortalidad en la infancia asociada a causas infecciosas (diarreas, respiratoria agudas, inmunoprevisibles) junto a la desnutrición y causas perinatales, cobran progresiva importancia las enfermedades de las edades adultas como las cardiovasculares, las neoplasias y las violentas. Sin considerar los valores de los índices, la 


\section{Lavulnerabilidad en lasetruaturasy procesosdemográficosdd Chaco}

variedad de situaciones epidemiológicas que existen en las distintas áreas de la provincia implica que habrá que dar énfasis a diversos aspectos de la salud de los distintos grupos etarios de la población.

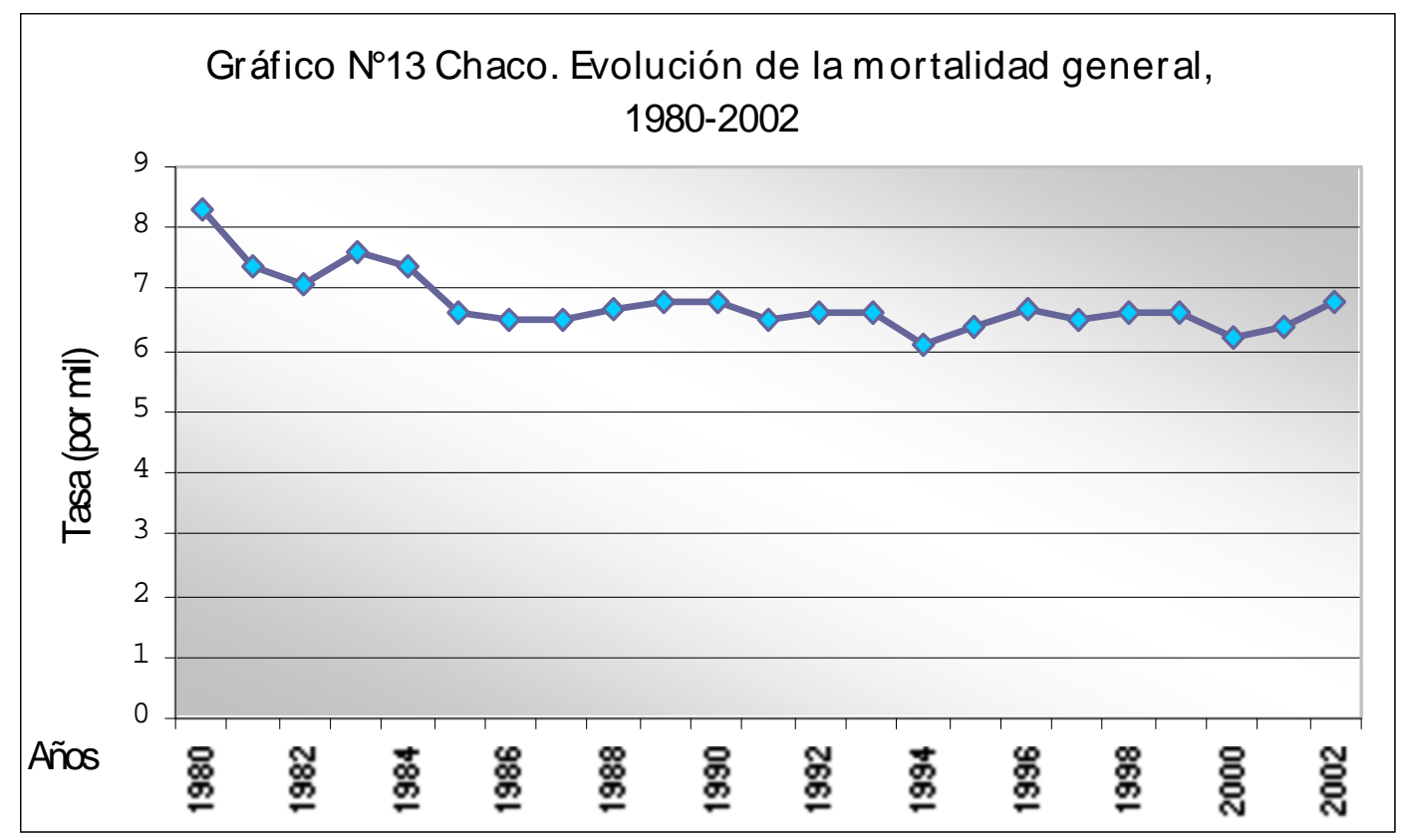

Fuente: Censos Nacionales de población, 1980, 1991 y 2001 Estadísticas vitales, 1980 a 2001.

Las figuras resultantes de la distribución de la mortalidad por edad muestran situaciones diferentes en la provincia:

- En el oriente provincial y parte del sudoeste la figura predominante es la tipo palo de hockey que revela un control riguroso de la mortalidad en la infancia y juventud aumentando hacia las edades adultas y ancianas. Ello se superpone con una estructura etaria de forma triangular, pera o campana, es decir con un control estricto de la natalidad.

- En numerosos sectores del centro y occidente se presenta la figura tipo $\mathrm{J}$ que muestra como rasgo distintivo la existencia de una mortalidad infantil importante.

- La tipo $U$ con una mortalidad infantil muy alta y muy similar a la registrada en las edades ancianas se localiza en algunos sectores del occidente y centro provincial

- La tipo $\mathrm{S}$ también se localiza en el sector occidental y representa un comportamiento de mortalidad similar en todas las edades. Estas tres últimas formas se corresponden con una estructura demográfica primitiva o Eiffel, y triangular con elevada natalidad. Mapa $\mathrm{N}^{\circ} 11$.

La ganancia de años en la esperanza de vida está relacionada principalmente con el descenso de la mortalidad infantil y de la niñez a raíz de la menor incidencia de las enfermedades infecciosas, parasitarias y del aparato respiratorio. La elevada mortalidad infantil se registra en las poblaciones cuyas madres tienen escasa o no tienen instrucción.

Si bien se viven modificaciones profundas en el cambio de las causas de muerte, existen rebrotes de enfermedades que aparentemente estaban superadas, como es el caso de la década de los 90 con el surgimiento de epidemias de enfermedades transmisibles como el cólera, la malaria, el mal de chagas, el hantavirus, la tuberculosis y el dengue, tanto en áreas rurales como urbanas, ocasionadas por la permanencia de la pobreza, la falta de servicios básicos y el alto grado de hacinamiento. 


\section{Lavulnerabilidad en lasetructurasy procesosdemográficosdd Cham}

En el campo de la salud y en estrecha relación con la transición demográfica se expone y desarrolla la denominada teoría de la transición epidemiológica. Esta expresa el cambio de las características de la morbilidad, las causas de muertes y la distribución por edad de las defunciones. El proceso consiste en la disminución proporcional de las muertes ocasionadas por enfermedades perinatales y las transmisibles (infecciosas, parasitarias y respiratorias) dando paso a las crónicas y degenerativas (tumores, circulatorias) y las provocadas por causas externas (violencia, accidentes, traumatismos), transformaciones que ocurren debido a cambios en el comportamiento en el plano de la salud, la nutrición, avances en la medicina y alteraciones socioambientales.. Asimismo hay un aumento proporcional de población adulta mayor y una baja de los niños.

Para estudiar el cambio de los patrones de salud y enfermedad Abdel Omram formuló la teoría de la transición epidemiológica donde asegura que los cambios en salud y los patrones de enfermedad están estrechamente vinculados con las transición demográfica y el nivel socioeconómico de las sociedades. ${ }^{19}$ Además plantea que el desarrollo histórico de la mortalidad se caracteriza por transcurrir por tres etapas diferentes: la edad de la peste y el hambre, la edad de las pandemias retraídas y la edad de las enfermedades degenerativas y las causadas por el hombre. ${ }^{20}$

Las condiciones de salud inciden directamente sobre la productividad (ausentismo laboral, envejecimiento prematuro, disminución de la vida activa) al mismo tiempo que influyen en las condiciones económicas (deterioro social e incremento de la pobreza). Un problema serio es el trabajo de los menores de 14 años, sector expuesto a factores de riesgo que derivan en cuadros patológicos que

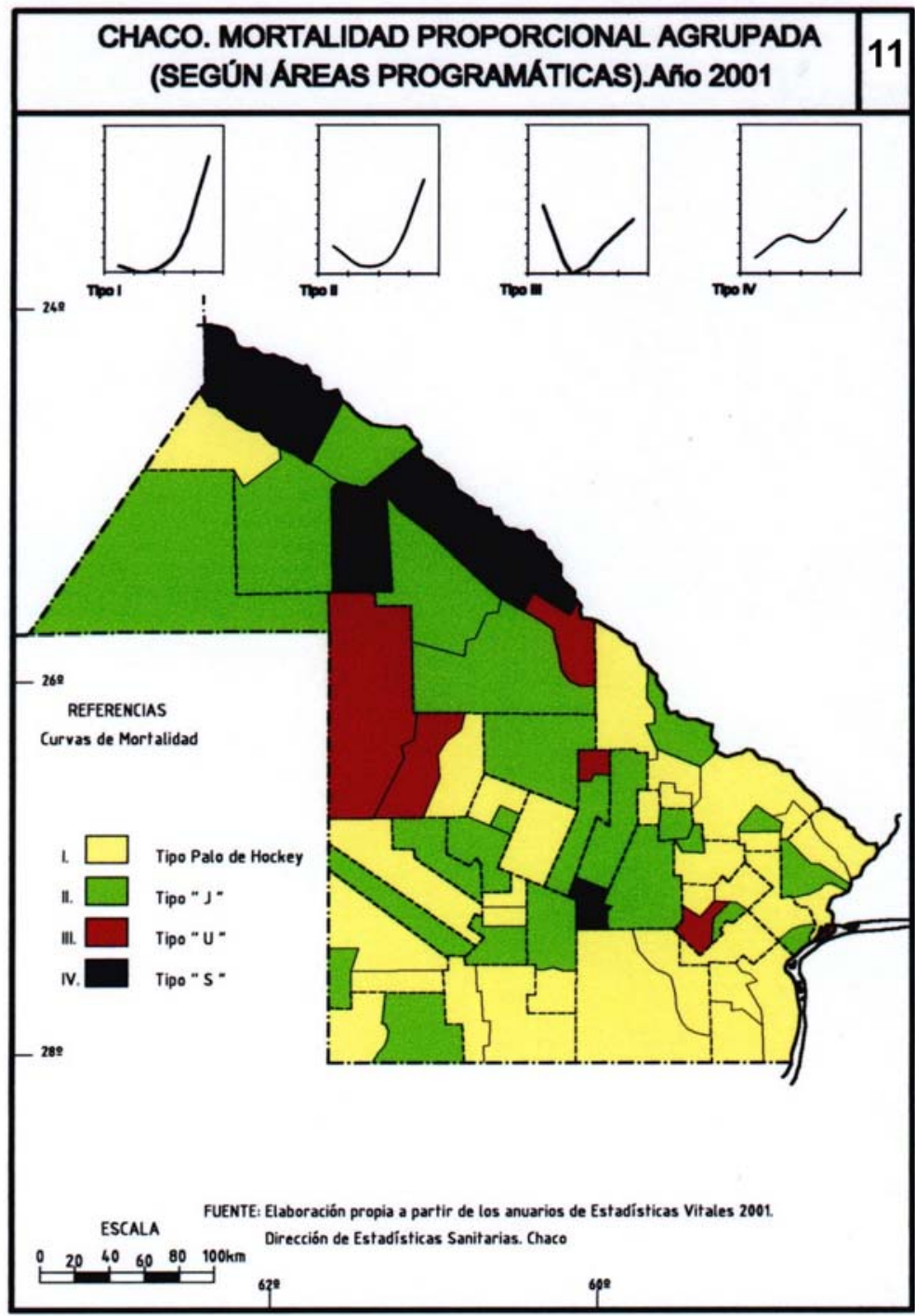
afectan las potencialidades futuras de la población activa. ${ }^{21}$

La mejora de las condiciones de salud de las mujeres y de los niños contribuirá a disminuir la mortalidad materna e infantil y a reducir indirectamente los niveles de fecundidad (especialmente embarazo adolescente). De esa forma, la salud y la educación son factores gravitantes para lograr el mejoramiento de los recursos humanos, tendiente a elevar los niveles de productividad. Así por ejemplo, la tasa de mortalidad materna en Argentina paso de 56 muertes de madres cada mil nacimientos en 1988 a 35 en el año 2000. América Latina tenía en promedio en 1995, 190 muertes c/1000 nacidos. ${ }^{22}$ 


\section{Lavulnerabilidad en lasetrudurasy procesosdemográficosdd Chaco}

En la transición epidemiológica (algunas veces referida como transición de la mortalidad o transición en salud) y estrechamente vinculada a la transición demográfica se pueden distinguir 4 fases: ${ }^{23}$

1. Primera fase: comprende la epidemiología de los países más pobres, con un predomi-

Mapa N¹2. Chaco. Esperanza de vida. 1996

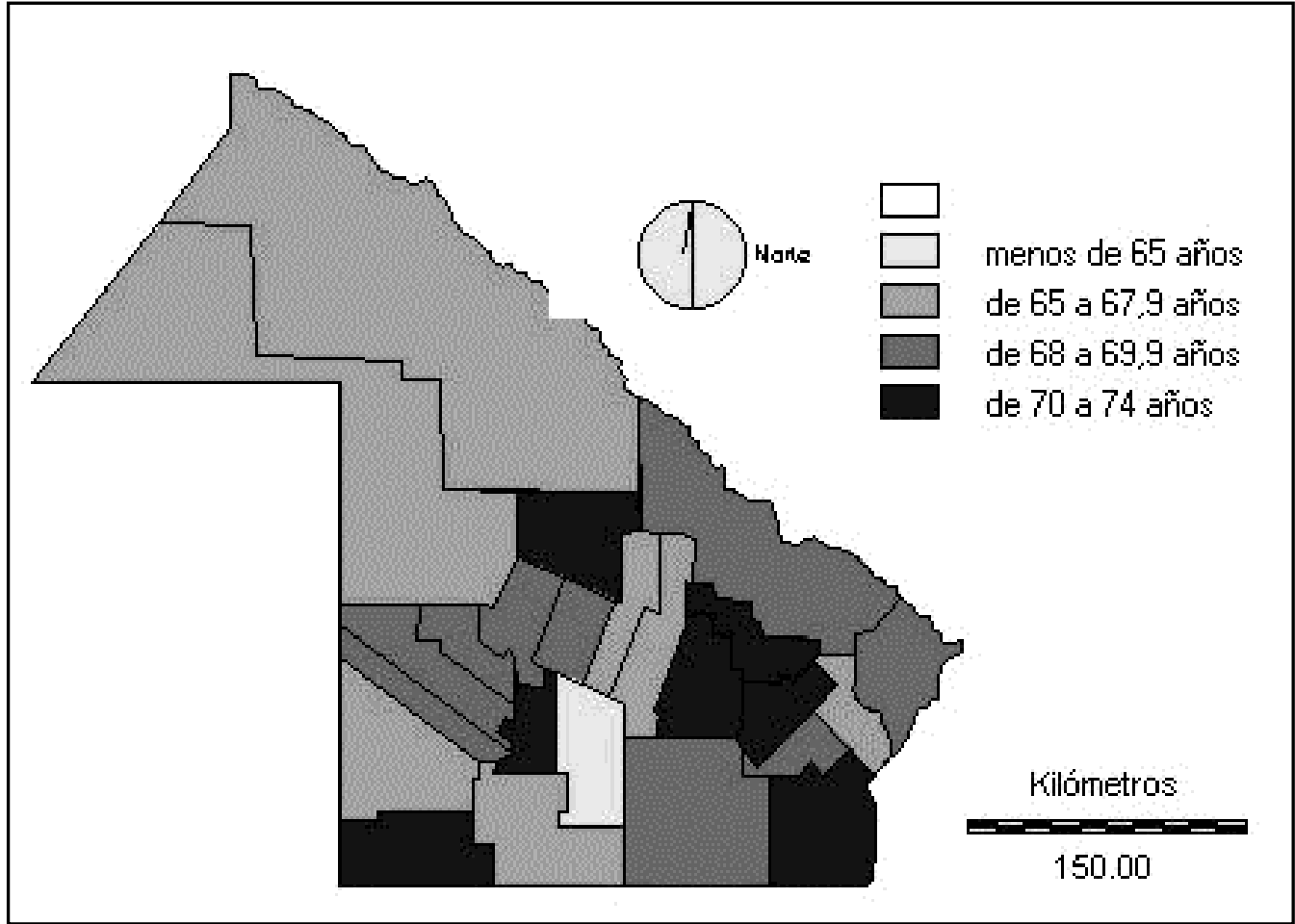

Fuente: Tomado de Ana María Foschiatti y Mirta Liliana Ramírez. La esperanza de vida en los países subdesarrollados. El caso de la provincia del Chaco en la Rca. Argentina. En: Revista Geográfica №127, México, IPGH, 2000. P.135

nio de enfermedades infecciosas y de la nutrición, con mortalidad infantil muy alta, mortalidad general baja por causas cardio-vasculares y esperanza de vida de la población corta. Los procesos degenerativos son poco frecuentes por los rasgos de la alimentación.

2. Segunda fase: Corresponde a los países en vías de desarrollo donde el mejor nivel socioeconómico se corresponde con una mejora en la alimentación y en las condiciones higiénicas y sanitarias, con lo cual disminuyen las enfermedades infecciosas (aunque con una importante prevalencia) y de la nutrición. Además aparecen en forma incipiente los factores de riesgo cardiovasculares y aumenta la incidencia de la arteriosclerosis.

3. Tercera fase: Incluye a los países en transición, donde el importante desarrollo económico acompaña a los cambios en la nutrición (alimentación rica en grasas, sal) y en el estilo de vida (vida sedentaria, aumento del estrés, la obesidad y el consumo de tabaco y alcohol). Ello conduce a la modificación de la distribución de las enfermedades, con mayores factores de riesgo cardiovasculares y accidentes cerebro-vasculares. Existe una mayor esperanza de vida y una disminución importante de las enfermedades infecciosas y de la nutrición.

4. Cuarta fase: Comprende a los países más desarrollados con mayores avances en la investigación médica y con la aplicación de medidas de educación sanitaria que ayudan a tomar conciencia a la población sobre el riesgo de las enfermedades cardiovasculares. De esa manera se disminuye el consumo de alimentos nocivos, se incentiva la 


\section{Lavulnerabilidad en lasetructurasy procesosdemográficos de Chaco}

práctica de los ejercicios físicos, se evita la obesidad, el estrés y el consumo de tabaco. Todo eso conlleva a la reducción de la morbilidad y mortalidad, como asimismo a la prolongación de la esperanza de vida. Sin embargo todavía existen diferencias entre las capas altas y bajas de esas sociedades.

La transición epidemiológica no siempre se presenta estrictamente en estas cuatro fases, sino que existen otros determinantes, distintos del nivel socioeconómico, que pueden alterar y acentuar la incidencia de las enfermedades sobre la población y, de esa forma, la vulnerabilidad a contraerlas aunque parezcan superadas.

Durante la misma los cambios más profundos en salud y enfermedad ocurren entre los niños y la mujeres, por ser los grupos más vulnerables a esos procesos. Al mismo tiempo esos cambios están estrechamente vinculados con las transiciones demográfica y económica que constituyen la compleja modernización. El envejecimiento de la población también desempeña un rol importante en el cambio de perfil epidemiológico, porque son los adultos mayores los más vulnerables a las patologías crónicas y a las enfermedades degenerativas. Así, ante una mayor esperanza de vida y una reducción de las enfermedades transmisibles y neonatales, la estructura epidemiológica va cambiando paulatinamente.

A propósito de las particularidades del cambio y su variación temporal, se distinguen tres modelos básicos de transición epidemiológica: ${ }^{24}$

1. El modelo oeste o clásico que describe un cambio gradual de tasas de mortalidad altas (30\%) y natalidad alta (40 a $50 \%$ ) a tasa bajas 10 y $20 \%$ respectivamente, como consecuencia de las mejoras sociales, ambientales y económicas y a la práctica de métodos de control de la natalidad, donde poco tiene que ver los adelantos en la medicina, por lo menos en las etapas iniciales.

2. El modelo acelerado tiene un comportamiento similar al anterior pero fue mucho más brusco el cambio debido a la trascendencia de la tecnología médica.

3. El modelo tardío presenta una mortalidad en descenso por efecto fundamental de la revolución médica en gran parte importada. La fecundidad tuvo un descenso tardío como consecuencia de la aplicación posterior de los métodos de control.

Este último puede ser asimilado a la provincia del Chaco donde las tasas de mortalidad a principios del siglo $\mathrm{XX}$, de alrededor del $18 \%$, pasan a principios del siglo XXI al $6 \%$ y la fecundidad disminuye muy fuertemente en la década del 30 y en forma lenta a partir de 1970.

\section{La vulnerabilidad asociada a la estructura de la población}

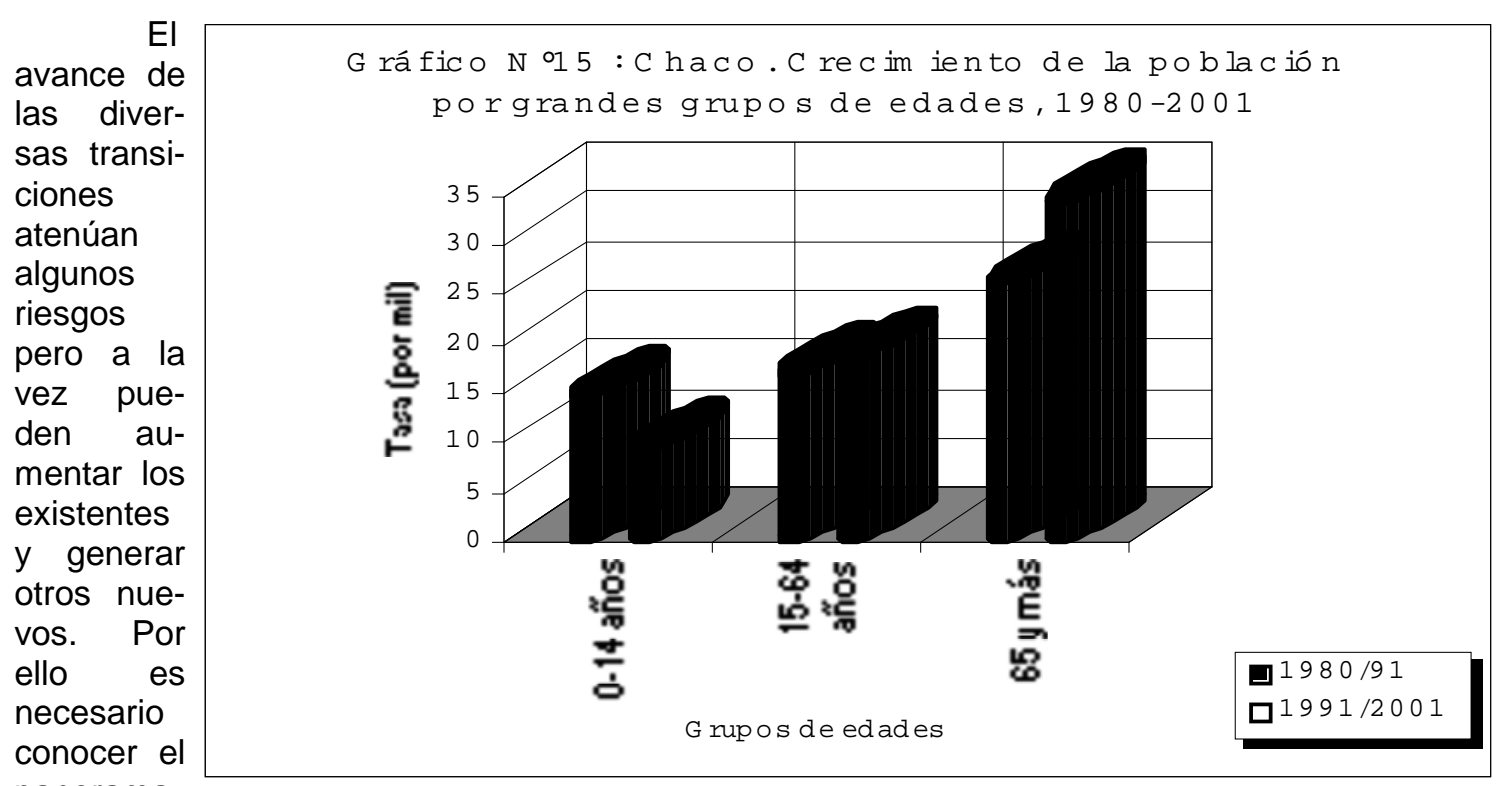

panorama 


\section{Lavulneabilidad en lasetructurasy procesosdemográficosdd Cham}

demográfico. Las tasas de crecimiento de la población del Chaco muestran diferencias en el análisis del total y por grupos de edades. Además no es uniforme en todo el ámbito provincial, lo cual supone algunos interrogantes sobre el futuro comportamiento regional en temas relacionadas con la edad media, la esperanza de vida, la fecundidad y la transformación de la estructura etaria.

Los nuevos riesgos generados por el proceso de transición demográfica modifican la estructura por edad de la población: la oscilación de las cohortes y el proceso de envejecimiento. El primero se origina en las variaciones del número de nacimientos que cambian el tamaño de los grupos de edades a medida que las cohortes avanzan en su ciclo vital. Es así que el descenso acelerado de la fecundidad causa grandes fluctuaciones en el tamaño de las mismas, especialmente cuando el descenso es irregular. Los riesgos que ello trae aparejado afec-

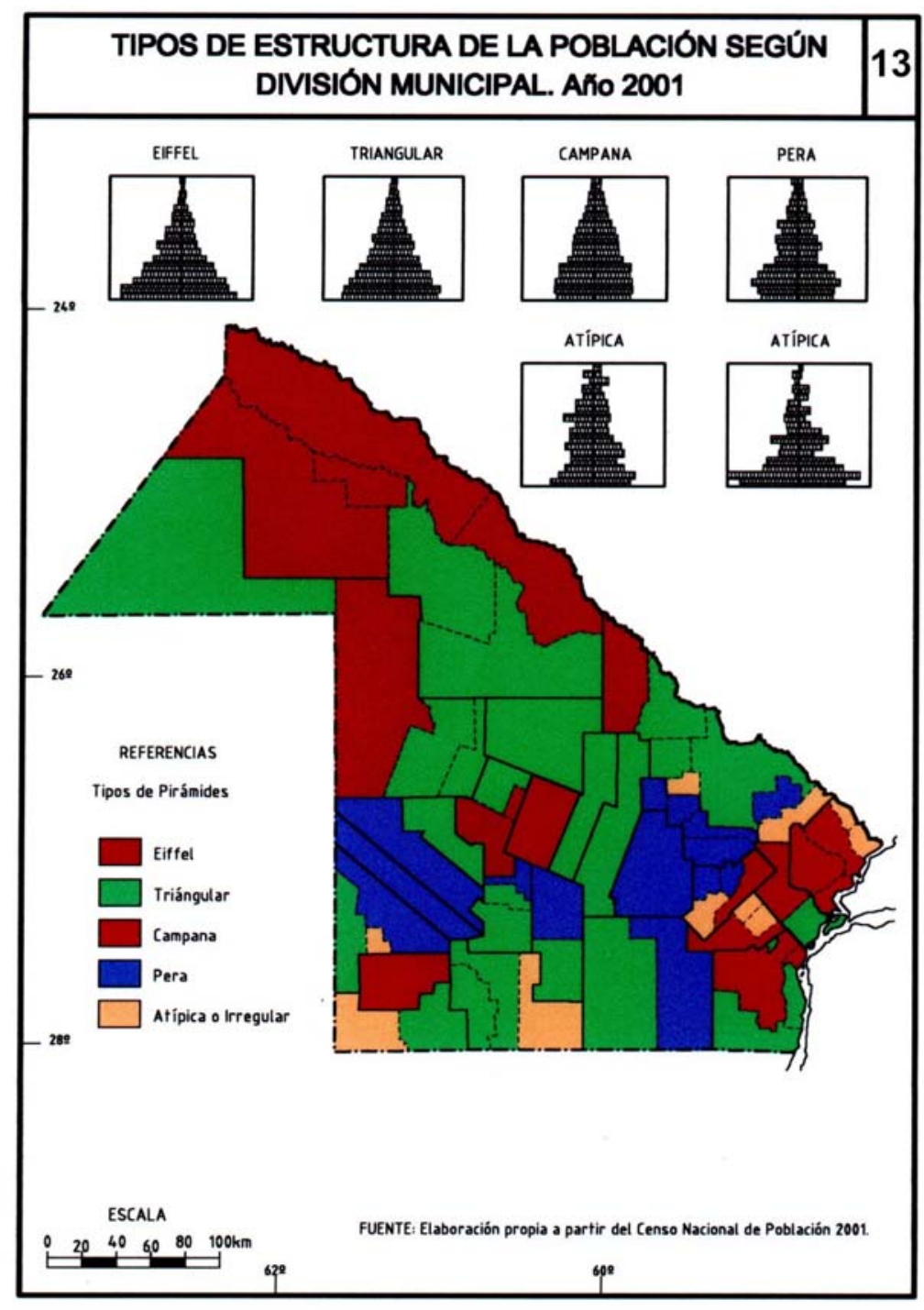

vimientos migratorios como así hechos extrademográficos que las definen.

Los modelos rítmicos están representados por tres tipos de pirámides: torre de Eiffel, triangular y campana y las arrítmicas por cinco: urna funeraria, rectangular o estacionaria, yunque, doble rectangular y atípica. A estas se pueden agregar dos más: forma de pera y gota (Leib-Mertins). ${ }^{26}$ munidades que están en proceso de transición demográfica.

La clasificación tradicional que expresa la composición demográfica distingue tres tipos de pirámides de población: Torre de Eiffel, campana y urna funeraria. Rey Balmaceda ${ }^{25}$ presenta una tipología más amplia donde es posible advertir una variedad más completa para el análisis: pirámides rítmicas y arrítmicas. Las primeras representan estructuras demográficas con un ritmo de disminución regular y sostenido, con una evidente simetría en los sexos. Las arrítmicas representan estructuras con anomalías en los distintos grupos $y$ entre los sexos. Ambas están afectadas por la natalidad, la mortalidad y los motan a todas las co- 


\section{Lavulnerabilidad en lasetruaturasy procesosdemográficosdd Chaco}

Algunos de esos tipos de pirámides se localizan en la provincia del Chaco mostrando los efectos de los hechos demográficos. En el sector occidental hay un predominio de pirámide tipo torre de Eiffel y triangular, hacia el oriente hay áreas con pirámides maduras o campana, pera y atípica. Al sudoeste hay un predominio de pera, triangular y atípica. Mapa № 13 .

El segundo riesgo es el envejecimiento cuyas consecuencias adversas se hacen sentir sobre las variables económicas, las finanzas, el perfil epidemiológico y la estructura social. Este proceso está en marcha en muchas regiones y muestra el aumento de la proporción y el volumen del grupo de población de 60 años y más. Aunque el envejecimiento cronológico es un riesgo inevitable, el demográfico puede manejarse mediante el control de los factores determi-

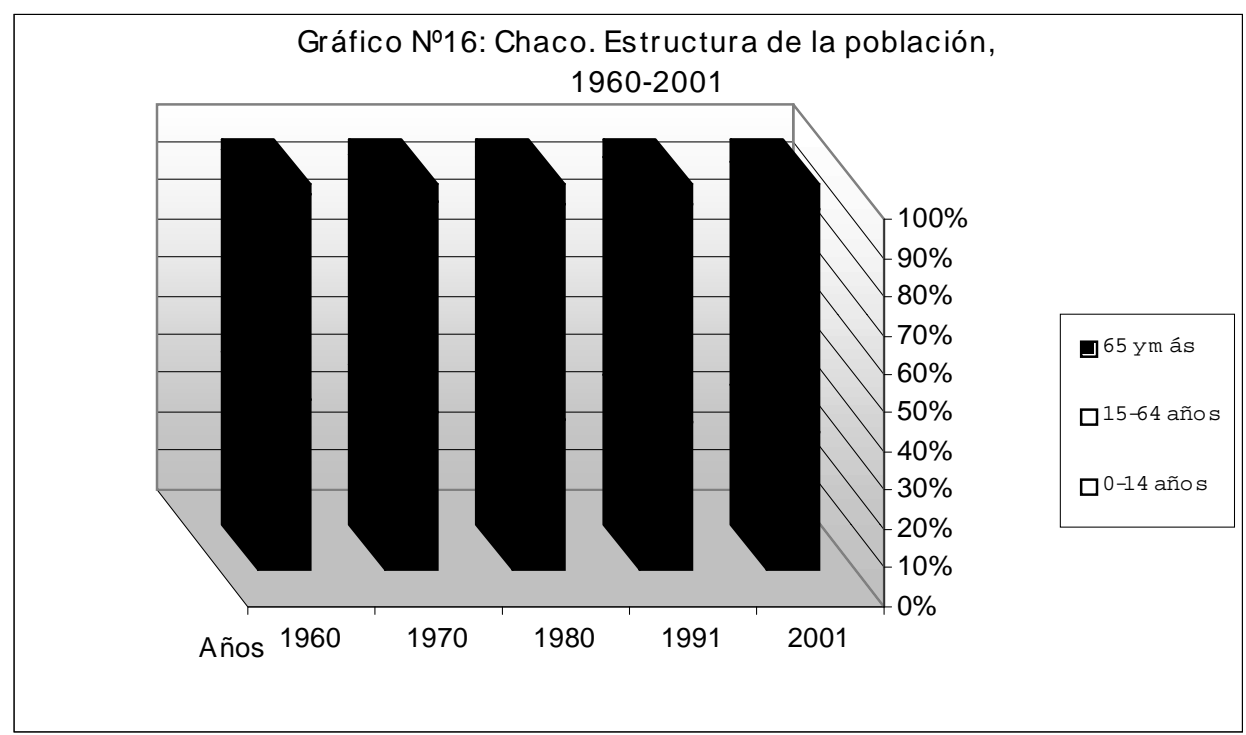

Fuente. Censos Nacionales de población

nantes, como la fecundidad y las migraciones. Dicho manejo depende de la capacidad de respuesta de las comunidades afectadas, y por lo general las áreas más envejecidas tienen niveles más altos de desarrollo aunque lejos del que presentan las áreas o países desarrollados.

Por otra parte no hay antecedentes de envejecimiento demográfico en un contexto de desarrollo precario.

En

otro orden de cosas, el envejecimiento puede considerarse como un riesgo con

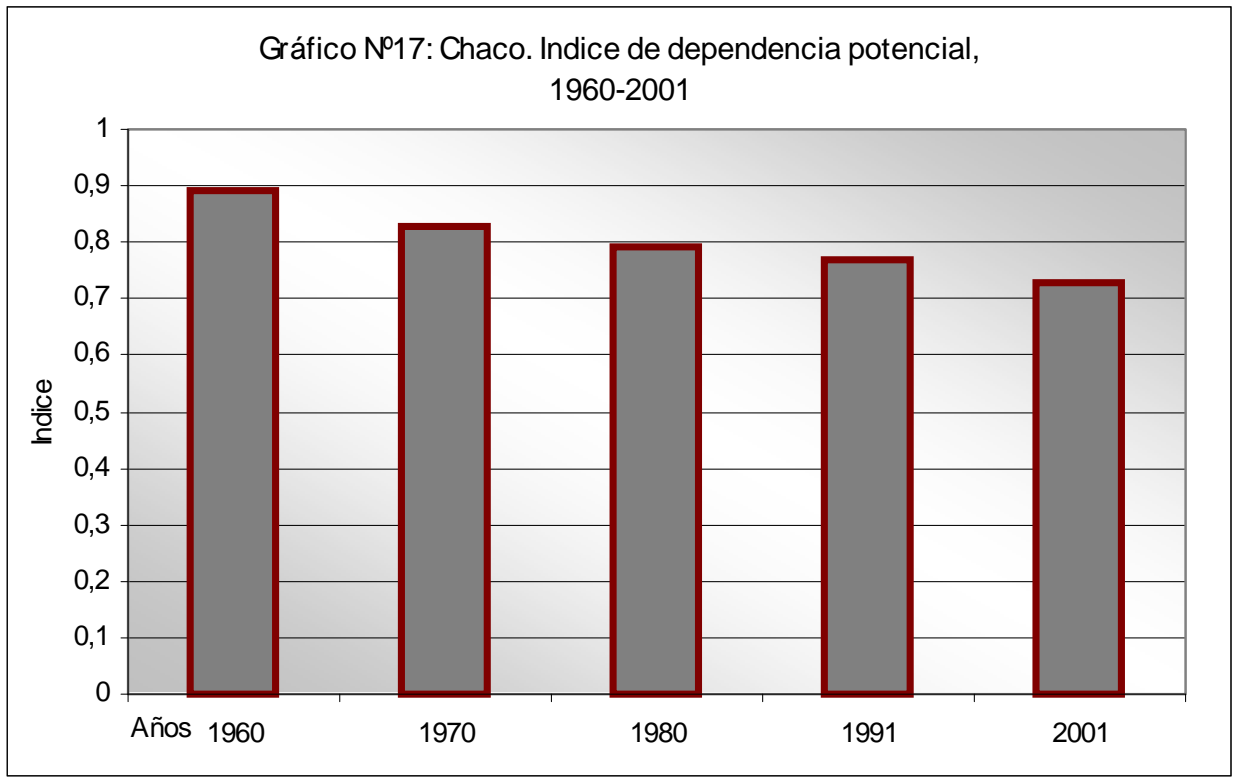




\section{Lavulnerabilidad en lasetruaturasy procesosdemográficosdd Chaco}

perfiles específicos en los hogares y en las personas, afectados por el comportamiento de la fecundidad y la mortalidad. Las adversidades que impone el envejecimiento se vinculan con la pérdida de recursos, con el deterioro físico y mental en las etapas finales de la vida. Es decir que el aumento de la expectativa de vida es una señal alentadora para la población, tanto por su significado intrínseco personal como socioeconómico; sin embargo no siempre el aumento de la duración de la vida va acompañado de un aumento de la calidad de vida, pues es cada vez mayor la cantidad de hogares y personas que envejece en un contexto precario.

A escala provincial y más aún en los ambientes rurales alejados de las áreas urbanas, varias características y condiciones demográficas pueden ser consideradas riesgos a corto plazo. Así por ejemplo los grupos con mayores desventajas son los hogares con más niños, por lo tanto con mayor dependencia, mayor hacinamiento y viviendas precarias con déficit en los servicios, con localización en áreas desfavorables y expuestas a riesgos ambientales, menor esperanza de vida, incremento de la fecundidad no deseada, especialmente en madres solteras y adolescentes.

La reducción de la tasa de crecimiento, el aumento de la edad media, el envejecimiento diseñan el futuro panorama demográfico que a su vez incide en el crecimiento económico y en las condiciones de pobreza. Los cambios en los índices de dependencia producto del avance de la transición demográfica a mediano plazo genera el denominado "bono demográfico" u "oportunidad demográfica" que implica una relación más holgada entre la población activa e inactiva (mayor fuerza de trabajo disponible, ahorros, inversión). De esa manera se espera que haya una reducción de las personas en edad no laboral, lo que implica mayor fuerza de trabajo, generación de ahorros, mejoras en la inversión y mayor ingreso per capita. ${ }^{27}$

\section{Reflexiones finales}

La noción de vulnerabilidad ayuda a comprender e identificar a los grupos humanos, hogares e individuos que por sus características comunes quedan expuestos a sufrir cambios significativos. Al mismo tiempo se relaciona con la línea conceptual de la marginación y la pobreza. La intensidad de esas relaciones es compleja, pues varían en función de los riesgos, no obstante ciertas características como la composición familiar, el equipamiento de las viviendas, la educación y la salud se vinculan con la posibilidad de estar expuestos a sufrir cierto grado de vulnerabilidad social.

Evidentemente los procesos de cambio de comportamiento de las variables demográficas, como así también, las transformaciones ocasionadas en las distintas transiciones, afectan a las poblaciones de manera diferente y de acuerdo con sus características sociales, económicas y ambientales. Es por ello que, de acuerdo al grado de vulnerabilidad global de los mismos, el análisis del comportamiento diferencial de los grupos humanos frente a los riesgos, debe contemplar la capacidad de respuesta ante ellos.

Cuanto mayor es el desarrollo socioeconómico en las áreas donde la transición está más avanzada, la vulnerabilidad sociodemográfica será menor, aunque si se analizan otros factores de problemática más compleja como los hogares con jefes mujeres, el envejecimiento, el subempleo, la desocupación se observarán que las desventajas sociales generan algún tipo de vulnerabilidad en buena parte de la población.

El avance de las distintas transiciones reduce algunos riesgos, pero no impide que otros persistan y algunos nuevos aparezcan, es decir la inestabilidad que contiene la dinámica demográfica no termina con la supuesta estabilización de la población. El análisis y la evaluación de las vulnerabilidades, realizados desde distintas ópticas permite detectar la susceptibilidad a los riesgos, diagnosticar la calidad de vida de la población en áreas espaciales localizadas y en sectores marginados de la población.

La vulnerabilidad demográfica interviene de manera compleja, con la totalidad de sus componentes o con sus alternativos. Además su vinculación con las desventajas sociales depende de la acción mutua de varios de sus elementos y no de uno solo de ellos. Por esa razón, 


\section{Lavulnerabilidad en lasetructurasy procesosdemográficosdd Chaco}

para detectar los síntomas de la vulnerabilidad en las estructuras y procesos demográficos se deben considerar la mayor parte de los antecedentes. Se propone para su evaluación, tomar en cuenta tres tipos de variables demográficas que interactúan con los factores sociales en las diferentes etapas transicionales (demográfica y urbana). El primero se relaciona con los atributos de las personas (edad, sexo, condición de actividad) el segundo con el tamaño y la composición de los hogares o viviendas (número de personas que lo integran, cantidad de niños, dependencia demográfica), y el tercero con las características demográficas y de distribución de la población de la sociedad en su conjunto (estructura, crecimiento), con los patrones de asentamiento y las migraciones.

Esa evaluación de la vulnerabilidad demográfica logra su doble propósito: por un lado reúne un conjunto de características de la población que generan desventajas sociales y, por otro, se asocia con otros factores que generan inconvenientes como es el caso de la pobreza, medida mediante las NBI, la disponibilidad de equipamiento y el nivel educativo del jefe del hogar, entre otros. El conocimiento del comportamiento diferencial de las distintas variables que afectan a los grupos humanos y la vulnerabilidad de los mismos frente a los hechos, permitirá esbozar estrategias sociales para conocer y mejorar las actitudes y prácticas de la población, como así formular recomendaciones, en base de la experiencia acumulada, e implementar políticas ambientales y sociales que mitiguen los riesgos.

\begin{tabular}{|l|c|}
\hline \multicolumn{1}{|c|}{ Factores generadores de vulnerabildad - CHACO - 2001 } & $\%$ \\
\hline Necesidades Básicas Insatisfechas & 27.6 \\
\hline Hogares & 33.0 \\
Población & 6.0 \\
\hline Atributo de las personas & 16.0 \\
Jefe/a menor de 24 años & 15.0 \\
Jefe/a de 65 años y más & 9.5 \\
Adolescente con experiencia reproductiva (mujeres entre 15 y 19 años) & 14.4 \\
Población entre 14 y 19 años con pareja & 8.0 \\
Mujeres entre 14 y 19 años con pareja & 52.0 \\
Población mayor de 10 años analfabeta (ambos sexos) & 65.5 \\
Mujeres mayores de 10 años analfabeta/total de analfabetos & 20.0 \\
Población sin obra social y/o plan de salud privado & 2.7 h/muj. \\
Mujeres mayores de 14 años con 5 o más hijos & 51.0 \\
Promedio de hijos por mujer & 36.7 \\
Población mayor de 14 años (PEA) & 14.3 \\
PEA ocupada & 81.0 \\
PEA desocupada & 19.0 \\
Jefes de hogar económicamente activos ocupados & \\
Jefes de hogar económicamente activos desocupados & \\
&
\end{tabular}




\section{Lavulnerabilidad en lasetructurasy procesosdemográficosdd Chaco}

\begin{tabular}{|c|c|}
\hline Población ocupada en actividades no productivas & 67.4 \\
\hline $\begin{array}{l}\text { Tamaño y estructura demográfica de las viviendas/hogares } \\
\text { Más de } 2 \text { personas por cuarto } \\
\text { Con } 7 \text { o más miembros por vivienda } \\
\text { Dependencia demográfica } \\
\text { Carga de población por cada jefe de hogar } \\
\text { Población sin servicio sanitario (inodoro sin descarga y sin inodoro) } \\
\text { Hogares con Jefe mujer / Total de hogares } \\
\text { Hogares unipersonales mujeres/ Total de Hogares unipersonales } \\
\text { Hogares multipersonales mujeres/Total de Hogares multipersonales } \\
\text { Jefes de hogar de núcleo incompleto } \\
\text { Jefe mujer con hijos y sin cónyuge/total de hogares monoparentales } \\
\text { Jefe varón con hijos y sin cónyuge/ total de hogares monoparentales }\end{array}$ & $\begin{array}{l}30.2 \\
14.2 \\
73.6 \\
4.1 \text { personas } \\
49.2 \\
\\
25.5 \\
43.2 \\
23.1 \\
80.4 \\
19.6\end{array}$ \\
\hline $\begin{array}{l}\text { Características demográficas de la provincia } \\
\text { Crecimiento Medio Anual intercensal (1991-2001) } \\
\text { Crecimiento Medio Anual intercensal urbano (1991-2001) } \\
\text { Crecimiento Medio Anual intercensal rural (1991-2001) } \\
\text { Estructura por grandes grupos de edades } \\
\text { 0-14 años } \\
\text { 15-65 años } \\
\text { Más de } 65 \text { años } \\
\text { Patrones de asentamiento territorial } \\
\text { Población urbana (2001) } \\
\text { Población rural (2001) } \\
\text { Proporción población de la capital resp. al total provincial } \\
\text { Saldo migratorio (1991-2001) } \\
\text { Tasa migratoria media intercensal (1991-2001) } \\
\text { Tasa de natalidad (1997-2001) } \\
\text { Tasa de mortalidad general (1997-2001) } \\
\text { Tasa de mortalidad infantil (2002) } \\
\text { Tasa de mortalidad en menores de } 5 \text { años (2002) } \\
\text { Tasa de mortalidad materna } \\
\text { Esperanza de vida }\end{array}$ & $\begin{array}{c}1.58 \\
2.60 \\
-1.65 \\
36.1 \\
57.8 \\
6.1 \\
\\
83.0 \\
17.0 \\
36.5 \\
-29.610 \\
-3.3 \% \\
24.4 \% \\
6.3 \% \\
26.7 \% \\
32.5 \% \\
15.9 \% \\
69.02 \text { años }\end{array}$ \\
\hline
\end{tabular}

Fuente: Elaboración propia en base a los Censos Nacionales de Población y Estadísticas vitales

\section{Notas}

1 El comportamiento de las variables demográficas y su relación con la vulnerabilidad es tratada por Brown, Dennis A.V. (2002) Vulnerabilidad sociodemográfica en el Caribe: examen de los factores sociales y demográficos que impiden un desarrollo equitativo con participación ciudadana en los albores del siglo XXI. Serie Población y Desarrollo N²5, Santiago de Chile, CELADE, Pp. $19-21$

${ }^{2}$ Chackiel, Juan. (2004) La dinámica demográfica en América Latina. Serie Población y Desarrollo, №52, Santiago de Chile, CEPAL, Pp.58-61

${ }^{3}$ Rivadeneira S, Luis. (2000) Op.cit. p. 22

${ }^{4}$ Chackiel, Juan y Schkolnik, Susana. (2003) América Latina: los sectores rezagados en la transición de la fecundidad. Serie Población y Desarrollo, №42, Centro Latinoamericano y Caribeño de Demografía (CELADE), Santiago de Chile. P.11

${ }^{5}$ Rodríguez Vignoli, Jorge. (2002) Distribución territorial de la población de América Latina: tendencias, interpretaciones y desafíos para las políticas públicas. Serie Población y Desarrollo No32, Santiago de Chile, CELADE. P.25

${ }^{6}$ Busso, G. (2002) op cit. P.38

${ }^{7}$ Zárate Martín, Antonio. Ciudad. Transporte y Territorio.Cuadernos de la UNED. Madrid, UNED, 1997. p.13.

${ }^{8}$ Ferrer Regales, Manuel. Los sistemas urbanos. №4, Madrid, Síntesis, 1992, p.29

${ }^{9}$ Ferrer Regales, Manuel. Los sistemas urbanos. №4, Madrid,, Síntesis, 1992. pág.29

${ }^{10}$ Pinto da Cunha, José Marcos. (2002) Urbanización, redistribución espacial de la población y transformaciones socioeconómicas en América Latina. Serie Población y Desarrollo N³0, Santiago de Chile, CELADE. P.7

${ }^{11}$ La Relación Rango-tamaño es un instrumento de análisis e interpretación que permite comparar la distribución jerárquica de las ciudades de un sistema urbano en la realidad, con su distribución ideal. Parte de la relación inversa observada por Averbach (1913) y comprobada empíricamente por J.Q. Stawart y G.K. Zipf (1944) entre el orden de cualquier ciudad dentro de un conjunto urbano y su población, consiste en que la población de orden o "rango r" es de $1 / n$ el tamaño de la población de la ciudad más poblada. La segunda ciudad posee $1 / 2$ la población de la primera, la tercera $1 / 3$, la cuarta $1 / 4$ y así sucesivamente. De ese modo los tamaños de todas las ciudades aparecen vinculadas entre sí y ponen de manifiesto las interrrelaciones existentes entre unas y otras. Según esta 


\section{Lavulnerabilidad en lasetrudurasy procesosdemográficosdd Cham}

regla se puede determinar el peso demográfico de cualquier ciudad conociendo el rango o lugar dentro del sistema urbano y el número de habitantes de la primera aglomeración. ${ }^{11}$ Dividiendo la población de la ciudad mayor por el rango de otra cualquiera del sistema se obtiene la población esperada de esa ciudad cualquiera. Por ejemplo, la población de una ciudad de rango 6 sería seis veces menor que la de la ciudad mayor del sistema (P1/6). Gutierrez Puebla, Javier. La ciudad y la organización regional. Madrid, Cincel, 1984, pp.56-64.

${ }^{12}$ Arriagada Luco, Camilo. (2003) La dinámica demográfica y el sector habitacional en América Latina. Serie Población y Desarrollo, No33, Santiago de Chile, CEPAL. Pp.20-23

${ }^{13}$ Arriagada Luco, Camilo. (2003) Op cit. P. 24

${ }^{14}$ Chackiel, Juan. (2004) La dinámica demográfica.... Op cit. P.15

${ }^{15}$ Esta expresión fue difundida por demógrafos europeos (Ron Lesthaeghe y Dirk van de Kaa -1986) para describir el conjunto de cambios en las conductas matrimoniales y reproductivas de Europa en la década de 1960.

${ }^{16}$ Rodríguez Vignoli, Jorge. (2001) Vulnerabilidad y grupos vulnerables: un marco de referencia conceptual mirando a los jóvenes. Serie Población y Desarrollo, No 17 , Santiago de Chile, CEPAL. P.5

${ }^{17}$ Cepal (2002) Vulnerabilidad... Separata.. Op cit Pág. 22-23

${ }^{18}$ Chackiel, Juan. (2004) La dinámica demográfica.... Op cit. P.62

19 “...aunque su tratamiento data desde sus estudios (1971), la terminología comienza a usarse en los diccionarios médicos hacia 1995. La premisa en esta teoría es que la mortalidad se constituye en un factor fundamental de la dinámica de la población y postula la transición de un patrón de causas de muerte por enfermedades infecciosas, con muy alta mortalidad, especialmente en edades jóvenes, a otro patrón dominado por las enfermedades degenerativas y las provocadas por la acción del hombre...” Vera Bolaños, Marta. (2000) Revisión crítica a la Teoría de la transición epidemiológica. Papeles de población №25, CIEAP/UAEM, México, pág.180-181.

${ }^{20}$ Las etapas se caracterizan por: a) en la edad de la peste y el hambre la mortalidad es alta y fluctuante, lo que provoca un crecimiento escaso de la población. Además la esperanza de vida es baja (entre 20 y 40 años).

b) En la edad de las pandemias retraídas las crisis de la mortalidad se vuelven menos frecuentes y la esperanza de vida se incrementa (entre 30 y 50 años). El crecimiento demográfico es sostenido.

c)En la edad de las enfermedades degenerativas y las producidas por el hombre, la mortalidad es baja y estable; la esperanza de vida aumenta hasta alcanzar a más de 50 años. La fecundidad es el hecho decisivo para controlar el crecimiento de la población.

Vera Bolaños, Marta. (2000) Op cit., pág. 181.

${ }^{21}$ Rivadeneira S, Luis. (2000) América Latina y el Caribe... op.cit. p.18

${ }_{22}^{22}$ Chackiel, Juan. (2004) La dinámica demográfica.... Op cit. P.50

${ }^{23}$ www.webmastersanitarios.org. La transición epidemiológica. 2004.

${ }^{24}$ Vera Bolaños, M. (2000) op cit, pág. 181-182

${ }^{25}$ Rey Balmaceda, R.C., Bardomás, Silvia. Estructuras de la población argentina y su distribución geográfica. PRIGEO, CONICET-OIKOS, Buemnos Aires, 1985. y Bolsi, A. Geografía de la población. Las estructuras demográficas, CEYNE, Buenos Aires, 1993

${ }^{26}$ La pirámide Torre de Eiffel responde a una natalidad elevada, con una base dilatada. La disminución de la población a medida que avanzan las edades se realiza en forma rápida como producto de una mortalidad elevada, sobre todo en los niños. El grupo de pasivos transitorios es elevado mientras que el de pasivos definitivos es muy reducido. La pirámide triangular tiene una forma regular y compacta, con una base mas restringida que la anterior y una disminución regular y constante a través de toda la figura. Responde a una natalidad y mortalidad media y el nivel de reemplazo es óptimo. La pirámide campana presenta una base más angosta que la anterior resultado de una natalidad y mortalidad media a débiles. Se engrosa el grupo de activos, disminuyen los pasivos transitorios y aumentan los definitivos. La pirámide urna funeraria corresponde a sociedades maduras con natalidad y mortalidad débiles. Acusa un envejecimiento en la base con una elevada proporción de adultos y ancianos. La pirámide rectangular representa a poblaciones envejecidas y casi estacionarias con débil natalidad y mortalidad y casi nulo crecimiento natural. La pirámide yunque corresponde a poblaciones que han sufrido alteraciones por factores no demográficos. La doble rectángulo presenta una lata natalidad y mortalidad, pero su rasgo distintivo es la concentración pronunciada que sufre la población activa a partir de los primeros años por efecto de la emigración. La de forma de pera presenta una disminución muy importante en la base como consecuencia de una baja en la natalidad por efectos de métodos de control, ya que el resto de la estructura se comportan en forma simétrica y con disminución escalonada. La de forma de gota presenta un vaciamiento de las edades jóvenes que resulta una natalidad casi nula, con un engrosamiento en las edades adultas y viejas. Las pirámides irregulares o atípicas presentan una asimetría en los sexos y en las edades con profundas irregularidades y desequilibrios que impide su inclusión y clasificación precisa.

${ }^{27}$ Busso, Gustavo (2002) Vulnerabilidad. sociodemográfica en Nicaragua: un desafío para el crecimiento económico y la reducción de la pobreza.. Serie Población y Desarrollo, №29, Centro Latinoamericano y Caribeño de Demografía (CELADE), Santiago de Chile. Pág. 39 